\title{
Roots drive oligogalacturonide-induced systemic immunity in tomato
}

\author{
Jordi Gamir ${ }^{1,2}$ (1) ～Z Zhivko Minchev ${ }^{1}$ ｜ Estefanía Berrio ${ }^{1} \quad$ | Juan M. García ${ }^{1}$ | \\ Giulia De Lorenzo $^{3}$ | Maria J. Pozo ${ }^{1}$
}

\begin{abstract}
${ }^{1}$ Department of Soil Microbiology and Symbiotic Systems, Estación Experimental del Zaidín (CSIC), Granada, Spain

${ }^{2}$ Present address: Metabolic Integration and Cell Signaling Group, Plant Physiology Section, Unidad Asociada a la EEZ-CSIC, Dept Ciencias Agrarias y del Medio Natural, Universitat Jaume I, Castellón, Spain

${ }^{3}$ Dipartimento di Biologia e Biotecnologie C. Darwin, Sapienza Università di Roma, Rome, Italy
\end{abstract}

\section{Correspondence}

Jordi Gamir, Department of Soil Microbiology and Symbiotic Systems, Estación Experimental del Zaidín (CSIC), Granada, Spain.

Email: jgamir@uji.es

Funding information

Consejo Superior de Investigaciones

Científicas, Grant/Award Number:

201840E130; Generalitat Valenciana, Grant/

Award Number: CDEIGENT/2018/015;

Ministerio de Ciencia, Innovación y

Universidades, Grant/Award Numbers: FJCl-

2015-23575, RTI2018-094350-B-C31;

Universitat Jaume I, Grant/Award Number: UJI-A2019-05

\begin{abstract}
Oligogalacturonides (OGs) are fragments of pectin released from the plant cell wall during insect or pathogen attack. They can be perceived by the plant as damage signals, triggering local and systemic defence responses. Here, we analyse the dynamics of local and systemic responses to OG perception in tomato roots or shoots, exploring their impact across the plant and their relevance in pathogen resistance. Targeted and untargeted metabolomics and gene expression analysis in plants treated with purified OGs revealed that local responses were transient, while distal responses were stronger and more sustained. Remarkably, changes were more conspicuous in roots, even upon foliar application of the OGs. The treatments differentially activated the synthesis of defencerelated hormones and secondary metabolites including flavonoids, alkaloids and lignans, some of them exclusively synthetized in roots. Finally, the biological relevance of the systemic defence responses activated upon OG perception was confirmed, as the treatment induced systemic resistance to Botrytis cinerea. Overall, this study shows the differential regulation of tomato defences upon OGs perception in roots and shoots and reveals the key role of roots in the coordination of the plant responses to damage sensing.
\end{abstract}

\section{KEYWORDS}

alkaloids, Botrytis cinerea, DAMPs, flavonoids, metabolomics, phytohormones, plant defences, systemic resistance

\section{INTRODUCTION}

Plants respond to invading organisms triggering fast signalling processes leading to the activation of diverse defence mechanisms. They have adapted their immune system to rely on an early molecular recognition of the potential aggressor, crucial for an efficient defence reaction (Jones \& Dangl, 2006). Immune responses are controlled by pattern recognition receptors, and defence signalling starts with the perception of conserved molecules associated to the damaging organism, such as pathogen (or microbe)-associated molecular patterns (PAMPs or MAMPs). Moreover, they can also recognize self- molecules associated to damage, the so-called damage-associated molecular patterns (DAMPs) (Zipfel \& Oldroyd, 2017).

DAMPs are damaged-self molecules released from host tissue disruption that act as endogenous danger signals in both animals and plants (Heil \& Land, 2014). DAMPs comprise a mixture of molecules from diverse origin such as extracellular nucleotides (eATP, eDNA and eNAD[P]), inducible proteins and fragments of the cell wall (Heil \& Land, 2014; Li, Wang, \& Mou, 2020). In plants, DAMPs are released from disintegrated cells and are sensed by the pattern recognition receptors of adjacent cells. After the recognition, plants go into an "alarm state" activating signalling cascades and triggering defence

This is an open access article under the terms of the Creative Commons Attribution License, which permits use, distribution and reproduction in any medium, 
responses not only locally, at the damaged tissue, but also in distal tissues that will then be prepared to respond more efficiently to a potential upcoming aggression (Orozco-Cardenas \& Ryan, 1999). Local responses to DAMPs involve the generation of $\mathrm{H}_{2} \mathrm{O}_{2}$, MAPKs activation, increased flux of calcium, production of phenylpropanoids and hypomethylation in CpG sites (Barbero, Guglielmotto, Capuzzo, \& Maffei, 2016; DuranFlores \& Heil, 2017; Pétriacq, Ton, Patrit, Tcherkez, \& Gakière, 2016; Vega-Muñoz, Feregrino-Pérez, Torres-Pacheco, \& Guevara-González,2018). Damage perception also involves cell-to-cell communication to prime distal parts of the plant. Consequently, plants activate a myriad of mobile signals that transmit the alarm state and activate defence responses over long distances. It has been reported that jasmonic acid (JA) signalling mediates some of the systemic responses in tomato plants after DAMPs perception (Sun, Jiang, \& Li, 2011). Generation of hydrogen peroxide, accumulation of proteinase inhibitors and other defencerelated proteins are produced in distal leaves upon wounding or application of the peptidic, wound-related hormone systemin in tomato (Orozco-Cardenas \& Ryan, 1999; Sun et al., 2011).

Oligogalacturonides (OGs) are among the best characterized plant DAMPs. They are pectin fragments hydrolysed from the cell wall that act as danger signals, triggering a signalling cascade that activates plant immunity (De Lorenzo, Ferrari, Cervone, \& Okun, 2018; Ferrari et al., 2013; Savatin, Gramegna, Modesti, \& Cervone, 2014). OGs are oligomers of $\alpha-1,4$-galacturonic acid that are released to the extracellular cell space through the action of polygalacturonases, usually generated during pathogens or insects attack (Benedetti et al., 2015). Exogenous application of OGs induces defence responses in plants when they have a degree of polymerization between 10 and 15 and they have acquired an egg-box conformational state dependent on calcium and sodium (Benedetti et al., 2015; Cabrera, Boland, Messiaen, Cambier, \& Van Cutsem, 2008). Short oligomers have been also shown to trigger plant defences, although to a lesser extent than long OGs (Davidsson et al., 2017).

It has been demonstrated that OGs perception stimulates antioxidant systems in plants (Camejo et al., 2012) and the biosynthesis of different antimicrobial enzymes through responses regulated by the main defence related phytohormones: JA, salicylic acid (SA) and ethylene (ET) (Bishop, Pearce, Bryant, \& Ryan, 1984; Denoux et al., 2008; Doares, Syrovets, Weiler, \& Ryan, 1995; Ferrari et al., 2007; Gravino, Savatin, Macone, \& De Lorenzo, 2015). These hormonal signalling pathways play a key regulatory function in the interaction of plants with potential aggressors as pathogens and herbivores (Pieterse et al., 2014). Therefore, the modulation of these pathways by OGs would likely have a relevant impact in these biotic interactions.

The ability of OGs to induce defence responses in plants stimulated the scientific community to study the potential of OGs for plant protection. In grape, pre-incubation of excised leaves with OGs leads to protection against the necrotrophic pathogen Botrytis cinerea (Aziz, Heyraud, \& Lambert, 2004), and protection was also achieved in Arabidopsis by spray-application of OGs (Ferrari et al., 2007; Galletti et al., 2008). Moreover, in-vivo production of bioactive OGs oligomers in Arabidopsis boosts plant defences and induces resistance to necrotrophic and biotrophic pathogens (Benedetti et al., 2015). Some research efforts have been devoted to analyse the plant responses to OGs that mediate this locally induced enhanced resistance. In Arabidopsis, OG-induced resistance against $B$. cinerea does not require JA and SA signalling, nor the oxidative burst generated in plants by OG perception (Aziz et al., 2004; Ferrari et al., 2007; Galletti et al., 2008; Galletti, Ferrari, \& De Lorenzo, 2011; Gravino et al., 2015). Instead, it requires a functional PAD3, which encodes the last step of camalexin biosynthesis (Ferrari et al., 2007. Based on previous evidences, formulations combining OGs with chitosan oligomers are already available for plant protection against pathogens (van Aubel, Cambier, Dieu, \& Van Cutsem, 2016).

Little is known about the responses induced by OGs at the systemic level, despite the well-established relevance of systemic defence responses in plants (Hilleary \& Gilroy, 2018). The first observations of the function of OGs as an elicitor of systemic responses were obtained in tomato (Bishop, Makus, Pearce, \& Ryan, 1981; Reymond, Grünberger, Paul, Müller, \& Farmer, 1995; Simpson, Ashford, Harvey, \& Bowles, 1998; Thain, 1995). However, the induction of systemic resistance to pathogens upon OG treatment has been so far reported only in Arabidopsis (Ferrari et al., 2007), although the molecular mechanisms behind this response are unexplored. Tomato was one of the model plants for the pioneer studies addressing systemic wound responses (Birkenmeier \& Ryan, 1998; O'Donnell et al., 1996; Schilmiller \& Howe, 2005) and tomato defence responses against $B$. cinerea are known to involve the wound related hormones JA, SA, ET and abscisic acid (ABA) (Achuo, Audenaert, Meziane, \& Höfte, 2002; Asselbergh et al., 2007; Curvers et al., 2010; Díaz, ten Have, \& van Kan, 2002; El Oirdi et al., 2011). Hence, an important question is how tomato plants respond not only locally but also systemically to OGs recognition and if these responses are able to trigger induced resistance (IR) against pathogens.

In this study we examined how tomato plants coordinate local and systemic responses to OG perception in different organs. In addition, we addressed the biological relevance of these responses by testing their efficacy in enhancing plant resistance against $B$. cinerea, a common and polyphagous necrotrophic pathogen. We show that changes in hormone levels induced by OGs are fast and transient at the local level and more sustained at the systemic level, and notably, that OGs have a stronger impact in roots than in leaves, regardless of the application site. Untargeted metabolomic analysis highlights the differential response to OGs in local and systemic tissues, supporting the notion of a precise fine-tuning of plant defences in response to this class of DAMPs, and uncovers the major pathways targeted by OG signalling. Finally, we show that root or leaf treatment with OGs induces systemic resistance against $B$. cinerea in tomato plants. The results highlight the differences among local and systemic responses and their dependence on the site of signal perception.

\section{2 | MATERIAL AND METHODS}

\subsection{Plant material and growth conditions}

Tomato seeds (Solanum lycopersicum, cv Castelmart) were surface sterilized in $4 \%$ sodium hypochlorite, rinsed thoroughly with sterile water and germinated for 3 days on moistened filter paper at $25^{\circ} \mathrm{C}$ in darkness. 
Subsequently, seedlings were transferred into $3 \mathrm{~L}$ plastic containers and grown hydroponically with water during the first week and with $0.5 \mathrm{x}$ Long Ashton nutrient solution (Hewitt, 1966) until the end of the experiment. The nutrient solution was replaced by fresh solution once a week.

\subsection{Oligogalacturonide treatments}

Oligogalacturonides (DP 10-15) were prepared as previously described (Benedetti et al., 2017): A PGA solution (2\% [w/v; Alfa Aesar]) was incubated with endo-polygalacturonase II (0.1 RGU/ml), purified from Aspergillus niger Pectinase (Sigma), for $180 \mathrm{~min}$ at $30^{\circ} \mathrm{C}$ in a water bath under gentle shaking. The digest was boiled for $10 \mathrm{~min}$ in a water bath to inactivate the enzyme and cooled at $4{ }^{\circ} \mathrm{C}$ on ice. Oligogalacturonides were precipitated by diluting the solution with cold $50 \mathrm{mM}$ sodium acetate and ice-cold ethanol to a final concentration of $0.5 \%(\mathrm{w} / \mathrm{v})$ PGA and $17 \%(\mathrm{v} / \mathrm{v})$ ethanol. The solution was incubated overnight at $4{ }^{\circ} \mathrm{C}$ and centrifuged at $30,000 \times g$ for $30 \mathrm{~min}$ to recover the pellet. This was solubilized and centrifuged at $30,000 \times g$ for $30 \mathrm{~min}$. The supernatant containing the oligogalacturonides was recovered, dialyzed against ultrapure water in a dialysis tube with a molecular mass cut-off of 1,000 Da (Spectra/Por $\left.{ }^{\circledR}\right)$ and lyophilized.

Four-week-old tomato plants were treated with aqueous oligogalacturonide solution $(50 \mu \mathrm{g} / \mathrm{ml}$ in milliQ water) either in leaves or roots. A time course analysis of the response was performed by harvesting leaf material at 1, 6 and $24 \mathrm{~h}$ after treatments. For leaf treatments (LT-), the fourth true leaf of each plant was sprayed with the oligogalacturonide solution using an aerograph until running off. Control treatments were carried out with water (CT-). Plastic was used to cover the rest of the plant during spraying to avoid contact of the solution with other plant parts. Water was applied similarly for the control treatment. Treated leaves were harvested at the different time points after treatment for the study of local responses (LT-TL). The sixth fully developed untreated leaf of each plant was also harvested to study systemic leaf responses (LT-SL), and the untreated roots were harvested to study root systemic responses to leaf treatments (LT-Root). For the root treatments (RT-), roots were incubated in a $50 \mu \mathrm{g} / \mathrm{ml}$ oligogalacturonide solution for $1 \mathrm{hr}$, water was used as control treatment. As for leaf treatments, different plant parts were harvested at 1,6 and $24 \mathrm{~h}$ following the incubation. Treated roots were harvested for local responses (RT-Root). The sixth fully developed untreated leaves were also harvested to study systemic responses in shoots upon OG root treatments (RT-SL). (Figure S1).

\section{3 | Phytohormones quantification. LC-ESI tandem mass spectrometry}

Six independent plants were harvested and stored at $-80^{\circ} \mathrm{C}$. The samples were freeze dried and powdered for subsequent analysis. Fifty milligrams of dry powder were used for hormonal extraction. Ultrapure water (Millipore, www.merckmillipore.com) was added containing a pool of internal standards abscisic acid-d6 (ABA-d6), salicylic acid-d5
(SA-d5) and jasmonate isoleucine-d6 (JA-lle-d6). Precise quantification was performed by using external calibration curves with each pure chemical compound. The content of the tube was vortexed and left at $4^{\circ} \mathrm{C}$ in order to hydrate the plant sample. Five glass beads $(2 \mathrm{~mm} \varnothing)$ were added into each microtube and the extraction was performed in a mixer mill at a frequency of $30 \mathrm{~Hz}$ for $3 \mathrm{~min}$. Tubes were centrifuged at $13,000 \mathrm{rpm}$ for $30^{\prime}$, and supernatant was recovered and placed into a new tube. A second extraction was then conducted, and the supernatant was added to the previous one. The $\mathrm{pH}$ was adjusted to 2.5-2.7 with acetic acid and the extraction was partitioned twice against diethyl ether. The two organic fractions were concentrated until dryness in a centrifugal evaporator (Speed vac) at room temperature. Samples were resuspended in $1 \mathrm{ml}$ of $\mathrm{H}_{2} \mathrm{O} / \mathrm{MeOH}$ (90:10) with $0.01 \%$ of $\mathrm{HCOOH}$ leading to a final concentration of internal standards of $100 \mathrm{ng} / \mathrm{ml}$. The chromatographic separation was carried out by injection of $20 \mu \mathrm{L}$ on an UPLC Kinetex $2.6 \mu \mathrm{m}$ particle size EVO C18 $100 \mathrm{~A}, 50 \times 2.1 \mathrm{~mm}$ (Phenomenex). The quantification of the plant hormones was done in an Acquity ultraperformance liquid chromatography system (UPLC; Waters, Mildford, MA), which was connected to a triple quadrupole mass spectrometer (TQD, Waters, Manchester, UK). The chromatographic and mass spectrometry conditions were those published by Gamir, Pastor, Cerezo, and Flors (2012). Masslynx v 4. 1(Waters, Manchester, UK) software was used to process the quantitative data obtained from calibration standards and samples.

\subsection{LC-ESI full scan mass spectrometry}

The metabolomic analysis was carried out with six biological replicates per treatment. Fifty milligrams of freeze-dried leaf or root material were extracted at $4{ }^{\circ} \mathrm{C}$ with $1 \mathrm{ml}$ of $\mathrm{MeOH}: \mathrm{H}_{2} \mathrm{O}$ (10:90) containing $0.01 \%$ of $\mathrm{HCOOH}$. After the centrifugation at full speed at $4^{\circ} \mathrm{C}$ for $15 \mathrm{~min}$, the supernatant was filtered through $0.2 \mu \mathrm{m}$ cellulose filters (Regenerated Cellulose Filter, $0.20 \mu \mathrm{m}, 13 \mathrm{~mm}$ D. pk/100; Teknokroma). Twenty microlitres were injected into an Acquity UPLC system (Waters, Mildford, MA) interfaced with a hybrid quadrupole time-of-flight instrument (QTOF MS Premier). Subsequently, a second fragmentation function was introduced into the TOF analyser to identify the signals detected. This function was programmed in a t-wave ranging from 5 to $45 \mathrm{eV}$ to obtain a fragmentation spectrum of each analyte (Gamir, Pastor, Kaever, Cerezo, \& Flors, 2014). To elute analytes, a gradient of methanol and water containing $0.01 \% \mathrm{HCOOH}$ was used. Six independent biological replicates per treatment were randomly injected. The LC separation was performed using an UPLC Kinetex 2.6 $\mu \mathrm{m}$ particle size EVO C18 100 A, $50 \times 2.1 \mathrm{~mm}$ (Phenomenex). Chromatographic conditions and solvent gradients and further were established as described by Gamir et al. (2014).

\section{$2.5 \quad$ Full scan data analysis}

Positive and negative electrospray ionization (ESI) signals were analysed independently to obtain a global view of the data conduct. 
For ESI positive, the instrument detected 5,927 signals and, for ES negative, 2,962 signals. The data files raw acquired with the Masslynx 4.1 software (Masslynx 4.1, Waters) were transformed into .cdf files with Databridge tool. Chromatographic data files were processed using the software R (http://www.r-project.org/). The XCMS algorithm (www.bioconductor.org; Smith, Want, O'Maille, Abagyan, \& Siuzdak, 2006) was used to obtain the peak peaking, grouping and signal corrections. Metabolite amounts were analysed based on the normalized peak area units relative to the dry weight. To test the metabolomic differences between treatments, a nonparametric Kruskal-Wallis test $(p<.01)$ was done. Partial least square discriminant analysis and heat map analysis were performed with the metaboAnalyst 4.0 (Chong et al., 2018). Adduct and isotope correction, filtering, clustering, exact mass mapping and metabolic pathway exploration was carried out with the packages MarVis filter, MarVis cluster and MarVis pathway that are integrated in the Marvis suit 2.0 (Kaever et al., 2014). Metabolite identification was carried out based on exact mass accuracy and fragmentation spectra matching with different online database. The database kegg (https://www.genome.jp/ kegg/) was used for exact mass identity and for fragmentation spectrum analysis, the Massbank and the Metlin databases were used (www.massbank.jp; www.masspec.scripps.edu).

\subsection{Quantitative RT-PCR analysis}

The expression of marker genes for the different defence related pathways was analysed by qRT-PCR using the gene specific primers shown in Table S1. Total RNA from leaves and roots was extracted using Tri-Sure (Bioline, London, UK) according to the manufacturer's instructions. The RNA was treated with NZY DNase I (NZYtech, Portugal), purified through a silica column using the RNA clean and concentratorm $^{\mathrm{TM}}$ (Zymo Research, Irvine, CA) and stored at $-80^{\circ} \mathrm{C}$ until use. The first-strand cDNA was synthesized with $1 \mu \mathrm{g}$ of purified total RNA using the Primescript ${ }^{\mathrm{TM}}$ RT master mix (Takara, Japan) according to the manufacturer's instructions. The qRT-PCR was conducted using the StepOnePlus ${ }^{\mathrm{TM}}$ (Applied Biosystem). Six independent biological replicates were analysed per treatment. We measured the expression of three different housekeeping genes, actin (Solyc03g078400), elongation factor 1- $\alpha$ (Solyc06g005060) and $\beta$-tubulin (Solyc04g081490) and, to find the optimal normalization gene among these three, we used the Normfinder software (https://moma.dk/normfindersoftware). According to the results, expression values were normalized using the housekeeping gene elongation factor $1-\alpha(E F-1 \alpha)$, and relative quantification of specific mRNA levels was performed using the comparative 2- $\Delta(\Delta C t)$ method (Livak and Schmittgen, 2001).

\subsection{Leucyl-aminopeptidase (LAP) and $\beta$-1,3-glucanase activity assays}

For protein extraction, $50 \mathrm{mg}$ of fresh plant material were extracted in the extraction buffer ( $50 \mathrm{mM}$ TRIS- $\mathrm{HCl}, 0.5 \mathrm{mM} \mathrm{MnCl}$, $\mathrm{pH}$ 8). One millilitre of the extraction buffer was added to each sample and was centrifuged for $20 \mathrm{~min}$ at $10,000 \mathrm{~g}, 4^{\circ} \mathrm{C}$. The supernatant was recovered and stored at $-20^{\circ} \mathrm{C}$. For LAP activity, Leu-p-nitroanilide (Sigma) was prepared from the stock solution as enzyme substrate at a concentration of $3 \mathrm{mM}$ in a solution of $50 \mathrm{mM}$ TRIS- $\mathrm{MnHCl}_{2}$. The stock solution was previously prepared at $150 \mathrm{mM}$ in ethanol and stored at $-20^{\circ} \mathrm{C}$. To carry out the analysis, $40 \mu \mathrm{L}$ of the protein sample and $200 \mu \mathrm{L}$ of the substrate were incubated for $15 \mathrm{~min}$ at $37^{\circ} \mathrm{C}$ and absorbance was measured at $410 \mathrm{~nm}$ as described in (Chao, Pautot, Holzer, \& Walling, 2000). $\beta$-1,3-glucanase activity was measured by the Somogy-Nelson method as described by Román et al. (2011).

\section{8 | Botrytis cinerea infection}

The fungus was cultivated in potato dextrose agar plates, supplemented with freeze-dried tomato leaves. Three weeks later, B. cinerea spores were collected from plates in $0.5 \mathrm{X}$ potato dextrose broth as previously described (Sanmartín et al., 2020).

Four-week-old tomato plants were treated with an aqueous solution of OGs in leaves (200 and $50 \mu \mathrm{g} / \mathrm{ml}$ ) or roots $(50 \mu \mathrm{g} / \mathrm{ml})$. Six hours after the treatment, treated leaves (for local responses) and the sixth fully developed untreated leaf (for systemic responses) of each plant were detached for the pathogen bioassays. Leaf inoculation was performed applying to the detached leaves $6 \mu \mathrm{L}$ drops containing a conidia concentration of $5 \times 10^{6}$ spores $/ \mathrm{ml}$. In total, we used the sixth fully developed leaf of 10 tomato plants. We inoculated four leaflets per leaf and we applied two drops per leaflet. Leaves were maintained in hermetically sealed boxes with $100 \%$ of humidity at $21^{\circ} \mathrm{C}$ in darkness. Necrotic lesions were evaluated after 5 days.

\subsection{Statistical analysis}

For the hormonal analysis and infection assays data a $t$-test was conducted using Microsoft office Excel. For qPCR data and enzymatic activity, a one-way ANOVA was used to find overall differences among the expression levels. Post hoc LSD was used to find significant differences among treated and control plants $(p<.05)$. All the metabolome profiling data were analysed using a Kruskal-Wallis analysis provided in MarVis suite 2.0.

\section{3 | RESULTS}

\section{1 | Treatment with OGs triggers local and systemic hormone responses in tomato roots and leaves}

The spatio-temporal regulation of local and systemic responses to OGs was analysed on tomato plants grown in a hydroponic system. An aqueous OG solution was applied to the fourth fully expanded leaf (leaf treatment; LT) or to the roots (root treatment; RT). Local 
responses were examined in the treated organs (local, leaves or roots). In the case of leaf treatment, systemic responses were analysed in roots and in the non-consecutive, fully developed younger leaf, attending to the vascular connection in tomato plants (Orians, Pomerleau, \& Ricco,2000) (sixth true leaf). In the case of root treatment, the equivalent sixth true leaf was harvested to study systemic responses (Figure S1).

First, we studied the changes in the main plant defence hormones and some precursors and derivatives (SA, ABA, ABA glucoside [ABAGluc], JA-lle and 12-oxo-phytodienoic acid [OPDA; JA precursor]). The levels of these compounds were measured at 1, 6 and $24 \mathrm{hr}$ post treatment (hpt) and the data are presented in Figure S2a-c. A summary of the changes, expressed as fold changes compared to the corresponding mock-treated controls is shown in Figure 1.

Local responses to OGs appear to be very different in leaves and roots (Figure 1). In treated leaves, changes were observed mainly at $1 \mathrm{hpt}$, consisting of a slight accumulation of ABA, an important accumulation of JA-lle (3.7 fold compared to mock-treated leaves) and a decrease of SA. A decrease of OPDA at $6 \mathrm{~h}$ was the only significant later response. In OG-treated roots only SA showed a change at $1 \mathrm{hpt}$ : a slight decrease, followed by a moderate increase at later time points. ABA transiently increased at $6 \mathrm{hpt}$, dropping below control levels at $24 \mathrm{~h}$.
Systemic responses of leaves to OGs were also different depending on the type of treatment (root or leaf) (Figure 1). A decrease of SA at all time-points and an accumulation of OPDA and ABA-Gluc levels at $6 \mathrm{hpt}$ were observed only upon leaf treatment, whereas a transient decrease of JA-lle was observed exclusively in RT-SL at 1 hpt. Levels of ABA-Gluc increased in systemic leaves with both treatments, with a delay in the case of root treatment.

Notably, systemic changes in hormone levels in the roots of leaftreated plants were more pronounced (Figure 1). A strong accumulation of JA-lle occurred at $1 \mathrm{hpt}$ that was maintained up to $6 \mathrm{hpt}$ and paralleled with a reduction of the JA precursor OPDA, revealing an upregulation of the oxylipin pathway in the roots upon leaf treatment. $A B A$ and its derivative $A B A-G l u c$ also showed a systemic transient increase in roots, and SA levels increased the latest time point.

These data show that tomato plants respond systemically to OG treatment in leaves, with the most conspicuous hormone changes occurring in the root. Regardless of the site of OG treatment (leaf or root), an early and transient increase of ABA and a late increase in SA occur mainly in roots. Instead, induction of the oxylipin pathway, shown as early increases in JA-lle levels, occurs in both leaves and roots only upon leaf treatments, although the effect is more durable in roots.

This hormone analysis was complemented with the expression analysis of genes involved in the JA, SA, ABA and ET biosynthesis

\begin{tabular}{|c|c|c|c|c|c|c|c|c|c|c|c|c|}
\hline \multirow{5}{*}{ 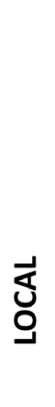 } & \multicolumn{2}{|c|}{ RESPONSE } & & & AV & & & \multicolumn{5}{|c|}{ ROOTS } \\
\hline & & & ABA & $\begin{array}{l}\text { ABA- } \\
\text { Gluc }\end{array}$ & SA & OPDA & JA-Ile & ABA & $\begin{array}{l}\text { ABA- } \\
\text { Gluc }\end{array}$ & SA & OPDA & JA-Ile \\
\hline & & $1 \mathrm{~h}$ & 1.3 & 0.8 & 0.3 & 1 & 3.7 & 1 & 0.8 & 0.8 & 1.2 & 1.2 \\
\hline & & $6 \mathrm{~h}$ & 1.1 & 1 & 0.6 & 0.3 & 0.4 & 2.1 & 2.4 & 1.3 & 0.8 & 1.4 \\
\hline & & $24 h$ & 0.9 & 1.5 & 0.6 & 3.7 & 1.2 & 0.3 & n.d. & 1.4 & 1.8 & 1.7 \\
\hline \multirow{6}{*}{ 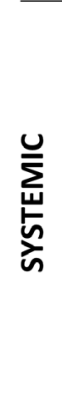 } & 17 & $1 \mathrm{~h}$ & 0.9 & 1.1 & 0.3 & 1.6 & 1.5 & 0.9 & 1.8 & 0.9 & 0.9 & 3.9 \\
\hline & & $6 \mathrm{~h}$ & 1.8 & 1.8 & 0.5 & 1.8 & 0.8 & 1.7 & 3.3 & 0.6 & 0.2 & 2.6 \\
\hline & (Leaf treatment) & $24 h$ & 0.8 & 2.4 & 0.5 & 3 & 0.8 & 0.2 & n.d. & 1.8 & 1.2 & 0.9 \\
\hline & & $1 \mathrm{~h}$ & 0.8 & 1.1 & 1.3 & 1.9 & 0.2 & & & & & \\
\hline & & $6 \mathrm{~h}$ & 1.1 & 1.3 & 1 & 1.2 & 1.1 & & & & & \\
\hline & (Root treatment) & $24 \mathrm{~h}$ & 1 & 2.1 & 0.3 & 0.9 & 1.1 & & & & & \\
\hline
\end{tabular}

FIGURE 1 Time course analysis of local and systemic changes in hormonal levels upon OG treatment in leaves or roots of tomato plants. Hormonal levels were quantified by UPLC-MS/MS at 1, 6 and $24 \mathrm{hr}$ in tomato plants elicited with OGs solution of $50 \mu \mathrm{g} / \mathrm{ml}$. For leaf treatments (LT), the fourth true leaf was sprayed with the OGs solution and samples from the treated leaf (local response-leaves-), upper leaf and roots (systemic response) were harvested at the different time points. For root treatments (RT) the OG solution was applied to roots and samples at the different time points were taken from roots (local response-roots-) and in the upper leaves for systemic responses (Systemic, RT). Hormone contents are shown in Figure S2a-c. Here, numbers represent fold induction in the hormone levels of treated vs control plants. Bold numbers indicate significant differences ( $t$-test; $p$-value <.05; $n=6$ ). Dark shading cells highlight significantly over accumulated compounds and, light shading cells highlight compounds that are significantly less accumulated 


\begin{tabular}{|c|c|c|c|c|c|c|c|c|c|}
\hline \multirow[b]{2}{*}{ Response } & \multirow[b]{2}{*}{ Time (hr) } & \multicolumn{4}{|c|}{ Leaves } & \multicolumn{4}{|l|}{ Roots } \\
\hline & & LOXD & PAL & NCED & ACO1 & LOXD & PAL & NCED & $A C O 1$ \\
\hline \multirow[t]{2}{*}{ Local } & 1 & 6.4 & 1.2 & 1.3 & 10 & 9 & 5.3 & 6.5 & 12.8 \\
\hline & 6 & 0.8 & 0.5 & 0.7 & 1 & 0.8 & 2.8 & 1.7 & 5.3 \\
\hline \multirow[t]{2}{*}{ Systemic (LT) } & 1 & 6 & 0.8 & 0.8 & 2.1 & 62 & 2.6 & 25.5 & 1.3 \\
\hline & 6 & 1.3 & 0.7 & 1.2 & 1.3 & 3.3 & 2.3 & 2.1 & 3.6 \\
\hline \multirow[t]{2}{*}{ Systemic (RT) } & 1 & 1 & 2.2 & 1 & 0.6 & - & - & - & - \\
\hline & 6 & 0.5 & 0.6 & 0.8 & 0.7 & - & - & - & - \\
\hline
\end{tabular}

TABLE 1 Transcriptional regulation of phytohormone biosynthetic genes upon OG treatment

Notes: Quantitative RT-qPCR analysis of LOXD (lypoxigenase D, involved in JA biosynthesis), PAL (phenylalanine ammonia lyase, involved in SA biosynthesis), NCED (9-cis-epoxycarotenoid dioxygenase, involved in ABA biosynthesis) and ACO1 (ACC Oxidase 1, coding for the enzyme responsible for the limiting step in ET biosynthesis) in leaves and roots of OG treated plants. Changes related to local responses were evaluated in treated leaves and roots. Systemic responses were evaluated in roots and upper leaves upon OG treatment in leaves (LT) or in upper leaves upon OG treatment in roots (RT). Numbers correspond to the fold induction of the gene expression levels in treated vs control plants $(n=6$ from six biological replicates). Values are normalized relative to the tomato housekeeping gene EF-1 $\alpha$. Bold numbers indicate significant differences and cells in italics highlight inducible values (one-way ANOVA; LSD; $p$-value <.05; $n=6$ ).

pathways (Table 1). In the local response, we observed an early and transient upregulation of the JA biosynthetic gene LOXD in both leaves and roots. In the systemic response, LOXD was induced only upon leaf treatment, with a stronger and more sustained induction in the roots than in upper leaves, confirming a general activation of the oxylipin pathway upon leaf treatment. In contrast, PAL (SA biosynthesis gene and the first step in the phenylpropanoid biosynthetic pathway) was only locally up-regulated in roots. As a systemic response, PAL was up-regulated in roots after leaf treatment and transiently in leaves after root treatment. Finally, induction of the ABA biosynthetic gene NCED was found mostly in roots as both a local and a systemic response to leaf treatment.

The role of ET in DAMPs signalling has been previously described (Díaz et al., 2002; O'Donnell et al., 1996; Simpson et al., 1998). For example, OGs treatments in tomato and Arabidopsis seedlings boost local ET levels and ET biosynthetic genes (Gravino et al., 2015; Simpson et al., 1998). Here, we examined the expression of the gene ACO1, well defined marker of ET pathway encoding the ACC oxidase 1, responsible of the limiting step in ET biosynthesis (Jafari, Haddad, Hosseini, \& Garoosi, 2013). ACO1 was markedly up-regulated as a local response in both leaves and roots. The induction was transient in OG-treated leaves, but stronger and more sustained in OG-treated roots. As a systemic response, ACO1 was induced in leaves only upon leaf treatment, showing a similar regulation pattern than the JA biosynthetic gene. Systemic induction in the roots was also observed upon leaf treatment. Thus, gene expression analyses confirm the activation by $\mathrm{OG}$ treatment of $\mathrm{JA}, \mathrm{ABA}$ and $\mathrm{ET}$ signalling, with varying patterns according to the application site. They also support the conclusion of a strong response to OGs in roots, either as a local or a systemic response (Table 1).

As a whole, the transcriptional and metabolic data reveal that OG treatment impacts hormone signalling both at a local and a systemic level with induction of the oxylipins, ABA and ET pathways. Local hormone-related responses to OGs in leaves occur early and transiently, while systemic responses are delayed compared to local ones, with the stronger effects detected at $6 \mathrm{hpt}$. Remarkably, changes in hormone levels and expression of hormone biosynthetic genes were, in general, stronger and more sustained during time in roots.

\subsection{OG perception modulates tomato plant metabolism in an organ-specific manner}

To characterize the responses elicited by OGs in tomato, we decided to carry out a non-targeted metabolomic analysis at $6 \mathrm{hpt}$, the time point showing the major changes according to the hormone profiles (Figure 1). For a global perspective, we conducted an unsupervised principal component analysis (PCA) (Figure S3). The component 1 , which explains the highest source of variability, clearly differentiated between root and leaf samples, coherent with specific metabolomic profiles in the different organs. Within leaves, variability was mainly related to the leaf age, since older leaves (fourth leaf, chosen for OG local treatment) and younger/upper leaves (true sixth leaf, chosen for the analysis of the systemic response) displayed very distinctive metabolic profiles, despite of being both adult, fully expanded leaves. Regardless of this difference, responses to OGs in leaves appeared much subtler than responses in roots (Figure S3). In roots, local and systemic responses to OGs showed marked differences (Figure S3).

For an exploratory approach, we decided to perform a sparse partial least square discriminant analysis (sPLS-DA). Variable selection in the sPLS-DA improves classification accuracy and characterization compared to classical PCA (Lê Cao, Boitard, \& Besse, 2011). A sPLSDA in leaves showed that OG treatments had a stronger systemic than local impact in the metabolic profile (Figure 2a). The systemic response was also different when OG treatment was applied to leaves 
(a)

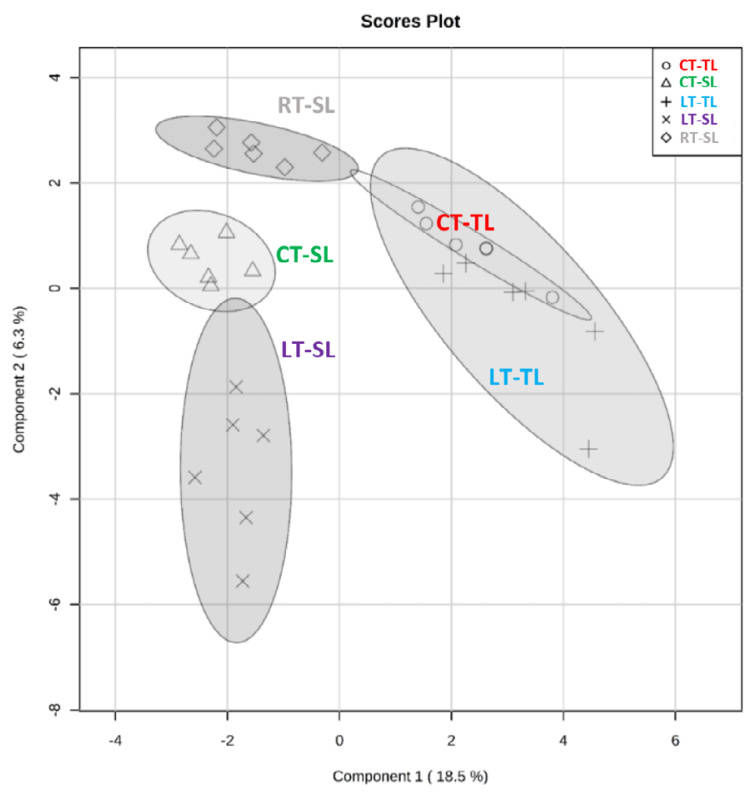

(b)

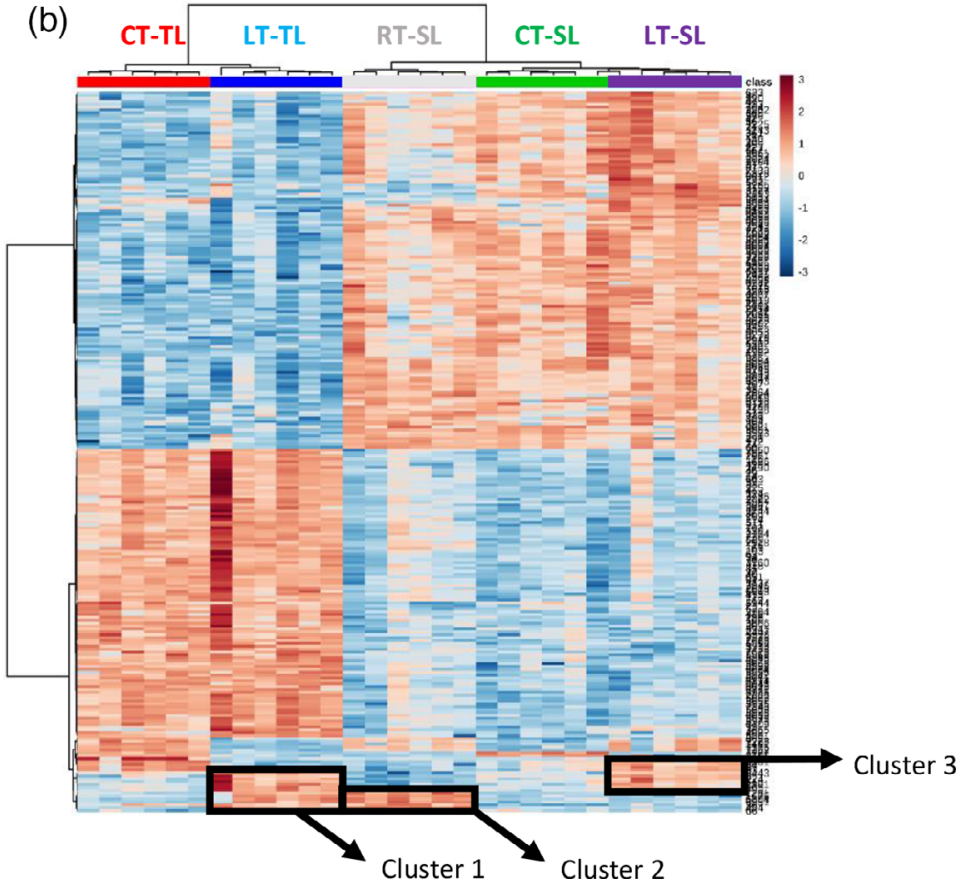

FIGURE 2 Impact of OG treatment on the leaf metabolic profiles (a) sPLS-DA representation of ESI- and ESI+ signals obtained from a nontargeted analysis by UPLC-QTOF to monitor metabolomic changes $6 \mathrm{hr}$ after OGs treatments. Three-week-old plants were treated in leaves or roots with a $50 \mu \mathrm{g} / \mathrm{ml}$ solution of OGs. Leaf samples were harvested $6 \mathrm{hr}$ post treatment. Data points represent six biological replicates injected randomly into the UPLC-QTOF. The signals corresponding to different treatments were compared using the non-parametric Kruskal-Wallis test, and only data with a $p$-value $<.01$ between groups was used for subsequent processing. (b) Heatmap analysis of leaf metabolites responding to OGs. Signals from ESI+ and ESI- with $p$-value <.01 were used to generate the heatmap analysis. The top 250 signals with the lowest $p$-value were selected to represent the heatmap. The relative amount of the metabolites was determined in all the samples by normalizing the chromatographic pick area of each compound with the dry weight of the corresponding sample. For control-treated plants with water (CT-) we analysed treated leaf response (CT-TL) and systemic leaf response (CT-SL). For OG leaf-treated plants (LT-) we analysed treated leaf responses (LT-TL) and systemic leaf responses (LT-SL). Finally, for OG root-treated plants (RT-) we analysed systemic leaf responses (RT-SL)

or roots. A heatmap analysis was carried out to identify the main features responsible for such differential profiles (Figure 2b). Different clusters showing signals with higher intensity due to OG treatments were selected for signal identification. Cluster 1 was selected to study local responses in leaves (LT-TL) and cluster 2 and 3 were selected for systemic responses: Cluster 2 for systemic responses in leaves after root treatments (RT-SL) and cluster 3 for systemic responses in leaves after leaf treatment (LT-SL). Tentative identification, based on exact mass accuracy and on-line fragmentation spectra of the signals was performed, and the pathways of the identified metabolites that are differentially accumulated in the different treatments are shown in Table 2. Remarkably, while almost 6 and 3.5\% of the total detected signals were significantly more accumulated in roots as a local or systemic response to OGs, respectively, only about $2 \%$ were significantly more accumulated in the local or systemic responses in leaves.

Regarding the metabolic pathways, local leaf responses to OGs included changes in flavonoid biosynthesis and in porphyrinchlorophyll metabolism (Table 2). Considering systemic leaf responses to root and leaf treatment, the comparison between cluster 2 (systemic, RT) and cluster 3 (systemic, LT) revealed that none of the signals tentatively identified were shared, explaining the difference observed in the SPLS-DA. Systemic leaf responses upon leaf treatment included flavonoid accumulation and changes in purine, amino acid and fatty acid biosynthesis. In contrast, systemic leaf responses to root treatment mostly involved tropane alkaloids, although it also impacted amino acids metabolism (Table 2). Remarkably, two of the three putative identified amino acids belong to the arginine and proline metabolism, known precursors of the tropane alkaloids biosynthesis.

In roots, the impact of OGs on the tomato metabolome is much stronger compared to that in leaves (Figure 3a). The heat-map analysis (Figure 3b) allowed us to pinpoint the cluster R1, corresponding to metabolites that strongly accumulated as a root local response to OG (RT-Root), and the cluster R2, corresponding to metabolites that accumulated in roots as a systemic response to leaf treatment (LT-Root). Tentative identification of the features in cluster $\mathrm{R} 1$ revealed that roots respond to OGs by accumulating flavonoids, alkaloids and lignans, all well-known antimicrobial metabolites (Table 2). In addition, auxin, biotin, lysine and terpenoids-quinone biosynthesis were also accumulated locally in treated roots. Noteworthy, biotin and lysine 
TAB LE 2 Pathways of identified metabolites differentially accumulated locally or systemically upon OG treatment in leaves or roots

\begin{tabular}{|c|c|c|}
\hline Response & Leaves & Roots \\
\hline \multirow[t]{8}{*}{ Local } & $(2 \%)$ & $(5.8 \%)$ \\
\hline & Flavonoid biosynthesis (3) & $\begin{array}{l}\text { Flavonoid biosynthesis } \\
\text { (4) }\end{array}$ \\
\hline & $\begin{array}{l}\text { Porphyrin and chlorophyll } \\
\text { metabolism (2) }\end{array}$ & Lignan (3) \\
\hline & & $\begin{array}{l}\text { Alkaloids biosynthesis } \\
\text { (3) }\end{array}$ \\
\hline & & Auxin degradation (2) \\
\hline & & Biotin metabolism (2) \\
\hline & & $\begin{array}{l}\text { Terpenoids-quinone } \\
\text { biosynthesis (2) }\end{array}$ \\
\hline & & Lysine biosynthesis (2) \\
\hline \multirow{5}{*}{$\begin{array}{l}\text { Systemic } \\
\text { (LT) }\end{array}$} & $(1.8 \%)$ & $(3.4 \%)$ \\
\hline & Flavonoid biosynthesis (3) & $\begin{array}{l}\text { Amino acid metabolism } \\
\text { (7) }\end{array}$ \\
\hline & Purine metabolism (2) & Dipeptide (3) \\
\hline & Amino acid metabolism (2) & Lignan (2) \\
\hline & Fatty acid biosynthesis (2) & \\
\hline \multirow{3}{*}{$\begin{array}{l}\text { Systemic } \\
\text { (RT) }\end{array}$} & $(2.2 \%)$ & \\
\hline & Alkaloids biosynthesis (3) & \\
\hline & Amino acid metabolism (3) & \\
\hline
\end{tabular}

Notes: The percentage of signals showing significantly higher accumulation from the total identified signals for a given treatment is shown in brackets. Identified metabolites were assigned to their corresponding metabolic pathways, and the number in the right refers to the identified compounds within that pathway. The signals corresponding to different treatments were compared using the non-parametric Kruskal-Wallis test, and only data with a $p$-value $<.01$ between groups were used for subsequent identification.

metabolism are related to the alkaloid biosynthetic pathways (Kegg pathway map00780). As a systemic root response to leaf treatment (cluster R2) lignans also accumulated, but mostly the amino acid metabolism was affected.

In summary, flavonoids accumulation was a common response to OGs in roots and shoots. Alkaloids accumulated only following root treatments, either locally in roots (RT-Root) or systemically in leaves (RT-SL), indicating that roots lead the responses related to alkaloids accumulation in all plant organs. As an example, the alkaloid putatively identified as anatalline accumulated in both roots and leaves of root treated plants (Figure S4), but did not change upon leaf treatment. On the other hand, lignans exclusively increase in roots both as local and systemic response, pointing to lignan accumulation as a common root response to OGs, regardless the site of perception. However, signals showing higher changes in the systemic root response were from the primary metabolism, suggesting a reorganization of root metabolism after the perception of danger signals in leaves.

\section{3 | Flavonoids and alkaloids biosynthetic genes are up-regulated in tomato roots as a local and systemic response to OGs}

Flavonoids and alkaloids, both accumulated in response to OGs, are phenylpropanoids derivatives that significantly contribute to plant resistance (Mithöfer \& Boland, 2012; Treutter, 2005). To gain further insight into the regulation of flavonoids and alkaloids in response to OGs, we studied changes in the expression of relevant biosynthetic genes at the local and systemic level 1 and $6 \mathrm{hr}$ after leaf or root treatment (Table 3). For the analysis, we chose CHALCONE SYNTHASE 1 (CHS.1.1), encoding the first enzyme of the flavonoid biosynthetic pathway that produces naringenin chalcone, CHALCONE ISOMERASE 1 (CHI1.1), responsible for the downstream reaction that converts naringenin chalcone to naringenin, and PUTRESCINE N-METHYLTRANSFERASE (PMT), encoding a key enzyme in the biosynthesis of tropane alkaloids (Biastoff, Brandt, \& Dräger, 2009; Petrussa et al., 2013).

In leaves, none of those genes showed any upregulation in the gene expression level in response to OGs at any of the timepoints tested regardless the OG application site. No expression of PMT was detected in leaves. In contrast, the expression of these genes showed significant changes in roots both as a local and a systemic response to the treatment. CHI1.1 and PMT were induced in roots as a systemic response to OG treatment in leaves (LT-Root). Interestingly, all three genes were down-regulated locally in roots $1 \mathrm{hpt}$ and strongly upregulated upon root treatment $6 \mathrm{hpt}$, with a particularly strong effect for CHS1.1 (59 fold). These results are in agreement with the metabolic analyses and collectively evidence the key role of roots in flavonoid and alkaloid biosynthesis following OG perception (Table 3 ).

\subsection{OGs induce systemic resistance to Botrytis cinerea}

The strong impact of OG treatment in systemic tissues at very early time-points prompted us to investigate whether OGs induce systemic resistance in tomato plants against the necrotrophic pathogen B. cinerea.

Systemic protection was examined by treating tomato roots or leaves with $50 \mu \mathrm{g} / \mathrm{ml}$ of OGs and infecting at $6 \mathrm{hpt}$ (the untreated true sixth leaf) with $B$. cinerea. Both root and leaf treatments (LT and RT) led to a significant reduction of the necrotic lesions compared to the corresponding control treated leaves (CT-SL), confirming that systemic responses to OG treatment are associated to systemic resistance against this pathogen in tomato. Remarkably, the protection level was similar regardless of the site of OGs application (roots or leaves) (Figure 4a).

Local OG-induced resistance was also examined, by inoculating the OG-treated leaves (LT-TL) at $6 \mathrm{hpt}$. No reduction of the necrotic symptoms was observed compared to control-treated leaves (CT-TL) at either $50 \mu \mathrm{g} / \mathrm{ml}$ or $200 \mu \mathrm{g} / \mathrm{ml}$ OGs (Figure 4b). Thus, under our experimental conditions and at the time point examined (6 hpt) OG treatment in tomato induced systemic but not local resistance to B. cinerea. 
(a)

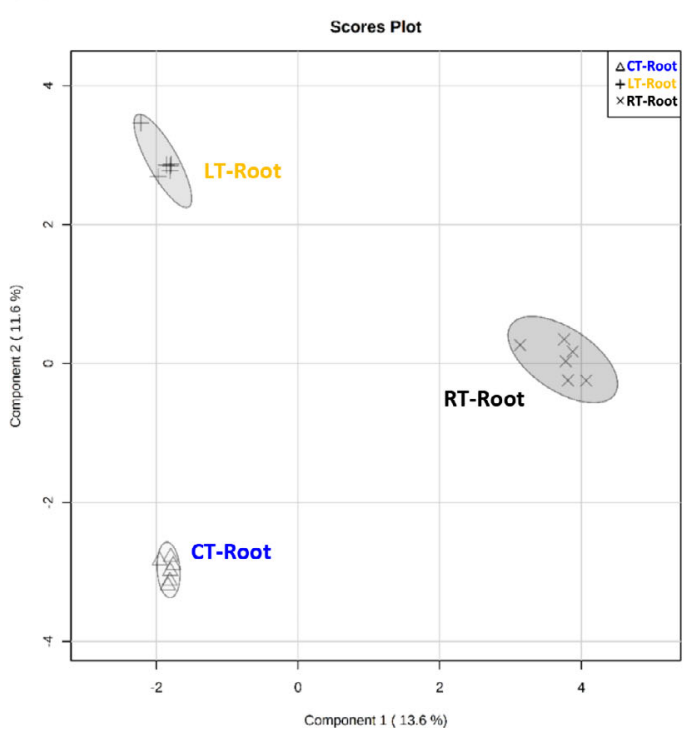

(b)

Cluster R2

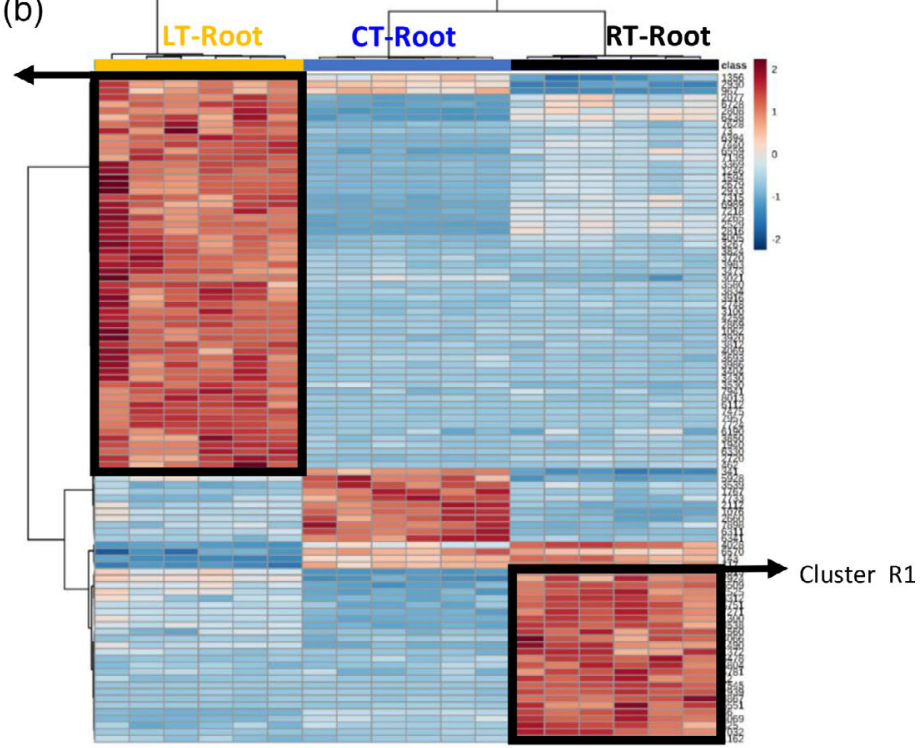

FIGURE 3 Impact of OG treatment on the root metabolic profiles (a) sPLS-DA representation of ESI- and ESI+ signals obtained from a nontargeted analysis by UPLC-QTOF-MS to monitor metabolomic changes $6 \mathrm{hr}$ after OGs treatments. Three-week-old plants were treated in leaves or roots with a solution of OGs $50 \mu \mathrm{g} / \mathrm{ml}$. Root samples were harvested $6 \mathrm{hr}$ post treatment. Data points represent six biological replicates injected randomly into the UPLC-QTOFMS. The signals corresponding to different treatments were compared using the non-parametric KruskalWallis test, and only data with a $p$-value $<.01$ between groups was used for subsequent processing. (b) Heatmap analysis of root metabolites responding to OGs. Signals from ESI+ and ESI- with $p$-value <.01 were used to generate the heatmap analysis. The top 100 signals with the lowest $p$-value were selected to represent the heatmap. The relative amount of the metabolites was determined in all the samples by normalizing the chromatographic pick area of each compound with the dry weight of the corresponding sample. For control-treated plants with water (CT-) we analysed root responses (CT-Root). For OG root-treated plants we analysed local root responses (RT-Root) and for OG leaf-treated plants we analysed systemic root responses (LT-Root)

TABLE 3 Transcriptional regulation of flavonoids and alkaloids biosynthetic genes upon OG treatment

\begin{tabular}{|c|c|c|c|c|c|c|c|}
\hline \multirow[b]{2}{*}{ Response } & \multirow[b]{2}{*}{ Time (hr) } & \multicolumn{3}{|l|}{ Leaves } & \multicolumn{3}{|l|}{ Roots } \\
\hline & & CHS1.1 & CHI1.1 & PMT & CHS1.1 & CHI1.1 & PMT \\
\hline \multirow[t]{2}{*}{ Local } & 1 & 0.9 & 1 & nd & 0.1 & 0.5 & 0.1 \\
\hline & 6 & 0.4 & 0.4 & nd & 59 & 5 & 7 \\
\hline \multirow[t]{2}{*}{ Systemic (LT) } & 1 & 0.4 & 0.7 & nd & 0.1 & 1 & 1.1 \\
\hline & 6 & 0.7 & 0.9 & nd & 0.4 & 2.6 & 3.6 \\
\hline \multirow[t]{2}{*}{ Systemic (RT) } & 1 & 0.8 & 1 & nd & - & - & - \\
\hline & 6 & 0.5 & 0.6 & nd & - & - & - \\
\hline
\end{tabular}

Notes: Quantitative RT-qPCR analysis of CHS1.1, CHI1.1 (flavonoid biosynthesis genes) and PMT (alkaloid biosynthesis gene) confirms upregulation of such metabolic pathways in roots in response to OGs treatments. Numbers correspond to the fold induction of the gene expression levels in treated vs control plants ( $n=6$ from six biological replicates). Values are normalized relative to the tomato housekeeping gene EF-1 $\alpha$. Expression levels of PMT in leaves were not detectable (nd). Bold numbers indicate significant differences and cells in italics highlight inducible values (one-way ANOVA; LSD; $p$-value $<.05 ; n=6$ ).

\section{5 | Antifungal defences are up-regulated as a systemic response to OGs}

Plant resistance to pathogens is generally the result of a combination of different defence mechanisms. Aiming to understand why the OG treatments induced systemic-but not local-pathogen resistance, we explored other potential antifungal defence responses that may contribute to the enhanced resistance against $B$. cinerea. Hence, we analysed the well characterized pathogenesis related proteins Leucyl aminopeptidase (LAP) and $\beta-1,3$-glucanases. LAP is a JA regulated, wound-responsive protein, displaying a dual role as aminopeptidase but also as a chaperone (Fowler et al., 2009; Scranton, Yee, Park, \& Walling, 2012). $\beta$-1,3-glucanases, are inducible enzymes with antimicrobial properties for their action on the $\beta$-glucans in fungal cell walls. 
(a)

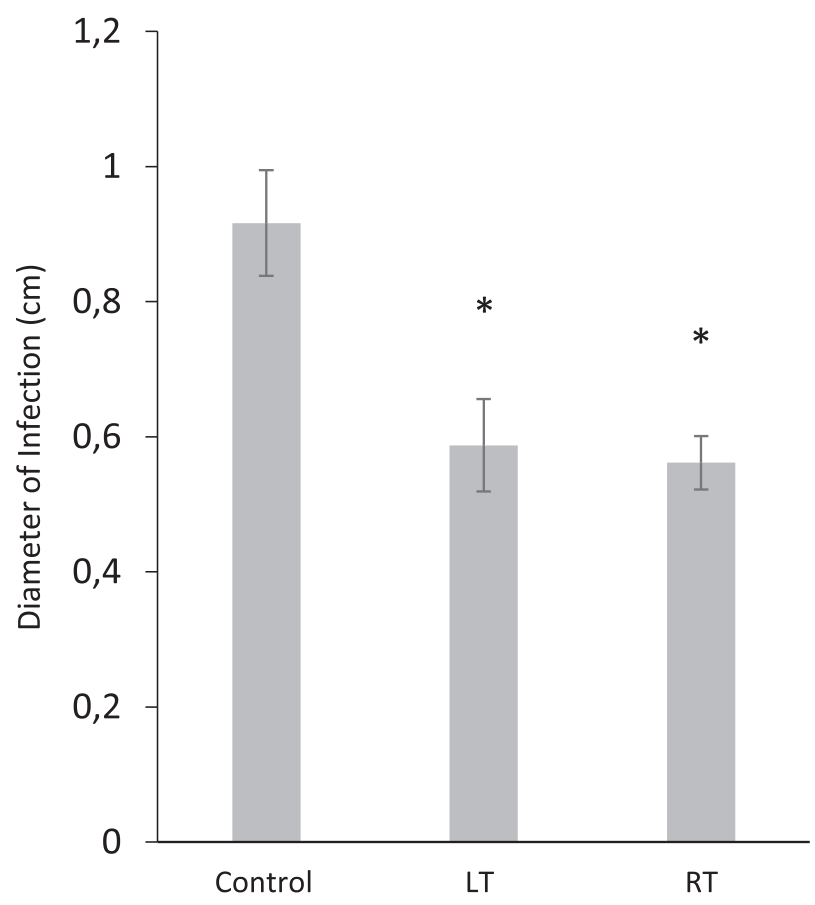

(b)

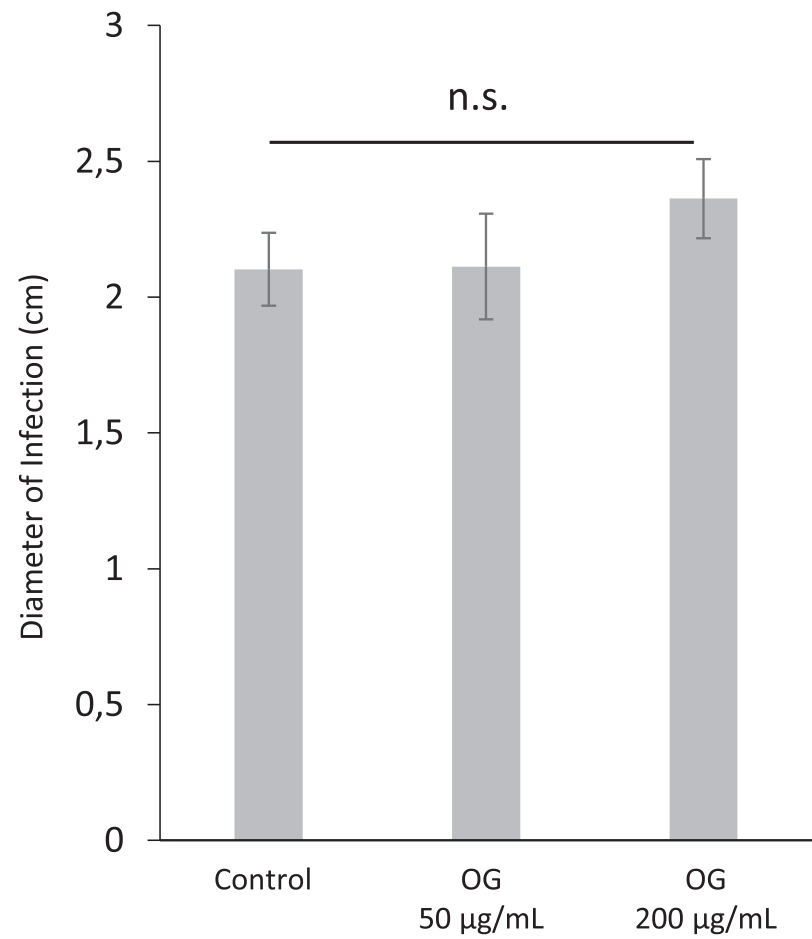

FIGURE 4 OG treatments induce systemic resistance against Botrytis cinerea. Three-week-old tomato plants were treated in roots with a $50 \mu \mathrm{g} / \mathrm{ml} \mathrm{OGs} \mathrm{solution} \mathrm{or} \mathrm{in} \mathrm{leaves} \mathrm{with} 50 \mu \mathrm{g} / \mathrm{ml}$ or $200 \mu \mathrm{g} / \mathrm{ml}$ OGs solution. Six hours after the treatment, plants were drop inoculated in upper or treated leaves with a Botrytis cinerea conidia suspension of $5 \times 10^{6}$ spore $\times \mathrm{ml}^{-1}$. Lesion diameter was measured 5 days after inoculation. Data presented shows the average lesion diameter \pm SE ( $n=10$ plants). Systemic leaf responses were analysed comparing upper untreated leaves from water-treated plants as control to upper leaves from OGs- leaf treated plants (LT) and to upper leaves from OGs-root treated plants in roots (RT). Asterisks indicate statistically significant differences compared to control plants ( ${ }^{*}$ water treated; $t$-test; $\left.p<.05\right)$

LAP activity was induced only in distal leaves in response to leaf OG treatment (LT-SL), whereas no changes were observed locally in treated nor upon root treatment (Figure 5a). Total $\beta$-1,3-glucanase activity did not vary among the different treatments (Figure S5). Several $\beta$-1,3-glucanases are present in tomato with differential regulation patterns, and total enzymatic activities may mask enhancement of specific glucanase isoforms. Thus, we examined the expression levels of $G$ luB, encoding a $\beta$-1,3-glucanase, known to be inducible by JA, ET and pathogens (van Kan, Joosten, Wagemakers, van den BergVelthuis, \& de Wit, 1992). While GluB expression was not induced in OG-treated leaves (local response), it was boosted in leaves as a systemic response to OG treatments in both leaves or roots treatments (Figure $5 \mathrm{~b}$ ). Note that the enhanced GluB expression correlates with the tissues showing OG induced resistance in the pathogen bioassay.

Taken together, our results suggest that the accumulation of defensive metabolites and the induction of pathogenesis-related proteins may underlie the efficient systemic protection against $B$. cinerea induced by OGs in tomato (Figure 6).

\section{4 | DISCUSSION}

DAMPs recognition and signalling is one of the earliest events of the plant and animal immune system (Heil \& Land, 2014). The relevance of DAMPs signalling in the immune responses has received increasing attention in the last years (De Lorenzo et al., 2018; Gust, Pruitt, \& Nürnberger, 2017) but our mechanistic and functional understanding of the process in plants is still very limited. Oligogalacturonides are DAMPs derived from the plant cell wall, and the responses they trigger have been mainly studied in Arabidopsis, at the local level (Davidsson et al., 2017; Gravino et al., 2017). In this study we investigated how tomato plants respond, both locally and systemically, to the perception of OGs in roots and shoots, and whether the systemic response to OGs confers resistance against $B$. cinerea.

Plant responses to OGs have been previously shown to be mediated by hormone signalling. For example, JA mediates some responses to OGs in tomato (Doares et al., 1995) and in Arabidopsis (Davidsson et al., 2017; Denoux et al., 2008; Ferrari, Plotnikova, De Lorenzo, \& Ausubel, 2003). Our time-course analysis of hormone changes in tomato plants after OG recognition reveals a complex regulation pattern both at the local and systemic level during the $24 \mathrm{hr}$ following OG application in roots or shoots. Hormone quantification complemented with gene expression analysis of related biosynthetic genes show the involvement of the JA, ABA and ET signalling pathways in the response to OGs. The activation of these pathways in response to these damage signals is in agreement with their reported regulation during the tomato wound responses (Tian, Peiffer, De Moraes, \& Felton, 2014). JA signalling was activated in leaves and roots upon leaf 
(a)

$\operatorname{LAP}(6 \mathrm{~h})$

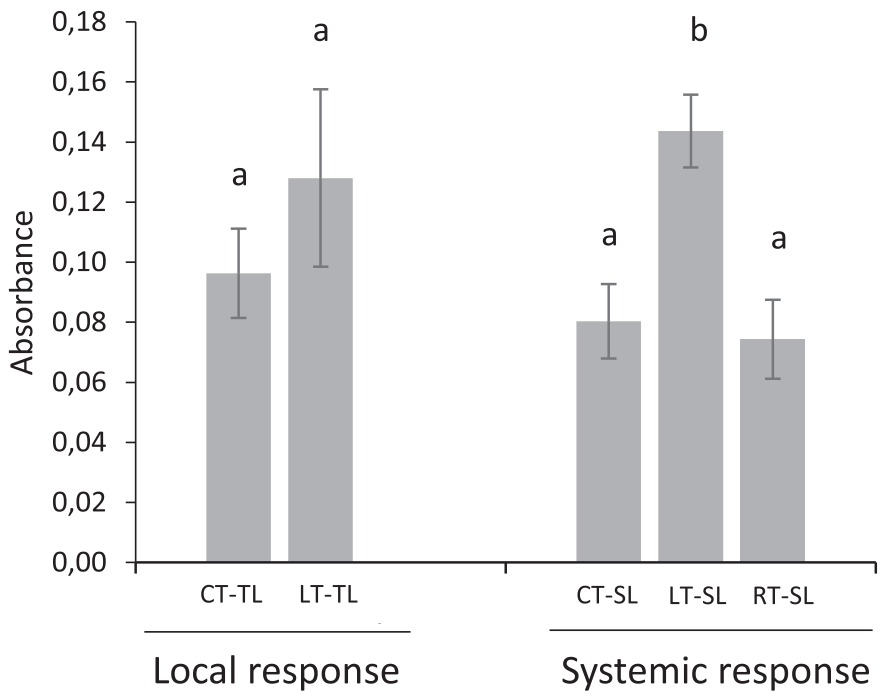

(b) GLUB(6h)

FIGURE 5 OG perception in leaves increases systemic leucyl aminopeptidase activity and $\beta$-1,3-glucanase GluB gene expression. Leucyl aminopeptidase activity (JA-responsive protein) and quantitative RT-qPCR analysis of GluB (coding for a pathogen inducible $\beta$-1,3-glucanase). Local responses were analysed in water-treated (CT-TL) or OG-treated leaves (LT-TL). Systemic responses were analysed comparing upper untreated leaves from water-treated plants as control (CT-SL) to upper leaves from OG-leaf treated plants (LT-SL) and to upper leaves from OGroot treated plants (RT-SL). Bars represent mean $\pm S D, n=6$ from six biological replicates. Different letters indicate statistically significant differences compared to control plants (one-way ANOVA; LSD; $p$-value $<.05$ )

(a)

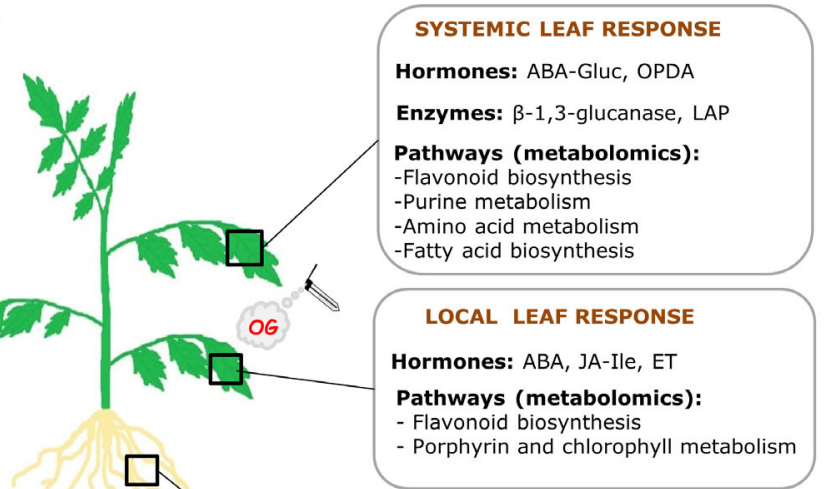

SYSTEMIC ROOT RESPONSE

Hormones:ABA, ABA-Gluc, JA-Ile, OPDA, SA, ET

Enzymes: PAL, CHI1, PMT

Pathways (metabolomics):

-Amino acid metabolism

-Dipeptide

-Lignan

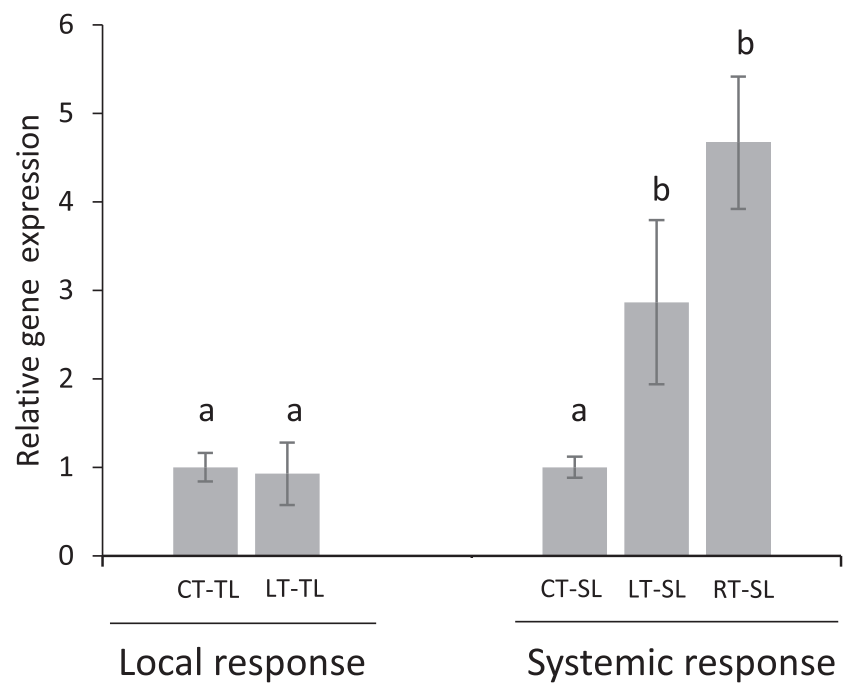


Remarkably, the untargeted metabolomic analysis showed that the most prominent response occurs in the roots of leaf-treated plants. Roots are the key regulators of plant defence responses to aboveground challenges; for example, foliar herbivory induces fast changes in roots leading to the synthesis of antiherbivore compounds such as alkaloids (Erb, Lenk, Degenhardt, \& Turlings, 2009; Erb, Meldau, \& Howe, 2012; Agut, Gamir, Jaques, \& Flors, 2016). Metabolic responses to OGs are stronger in roots than in leaves and, in the same line, the proportion of identified compounds over-accumulating after OG treatment is also higher in roots than in leaves. Similarly, JA accumulation in tomato leaves after the attack of the root-knot nematode Meloidogyne incognita depends on the production of electric signals and ROS accumulation in roots (Wang et al., 2019). In conclusion, our results support that damaged-self recognition impacts the root metabolic composition altering aboveground responses.

A detailed analysis of the changes in the metabolomics profile showed accumulation of phenylpropanoid compounds such as lignans and flavonoids in response to OGs. Lignans accumulated only in roots both as a local or systemic response and have been recently related to plant defence. Overexpression of a lignan biosynthesis gene in soybean roots induced resistance against the oomycete Phytophthora sojae (Li et al., 2017), and we have recently shown that the root derived lignan yatein is involved in mycorrhiza induced resistance against B. cinerea in tomato (Sanmartín et al., 2020). In contrast to lignans, flavonoids accumulated in roots only as a local response to OGs, and in leaves as both local and systemic response to leaf treatment. Interestingly, this is not the first indication of flavonoid accumulation after DAMPs perception. For example, foliar application of chitosan oligomers and OGs (COS-OGA) induced PAL in rice roots and shoots, (Singh et al., 2019). Additionally, untargeted metabolomic analyses showed that flavonoids are accumulated in Arabidopsis leaves after NAD+ treatments (Pétriacq et al., 2016). We further found that the flavonoid biosynthetic genes are strongly up-regulated in the roots, after local or distal OG treatments, but not in leaves. These results are in agreement with the finding that flavonoids synthesized in Arabidopsis roots after OG perception can be transported through the plant (Hernandez-Mata et al., 2010; Petrussa et al., 2013). Together, we suggest that lignans and flavonoids are synthetized in roots after OG recognition, and flavonoids are transported through the vascular system to the distal parts of the plants.

We also found an accumulation of tropane alkaloids as a local response in roots and as a systemic response in leaves, but only upon root treatment. Indeed, the putatively identified anatalline, a JAinducible tropane, piperidine and pyridine alkaloid (Häkkinen et al., 2004) showed elevated levels in roots and leaves of root treated plants, but no change upon leaf treatment. The role of alkaloids in plant defence has been extensively studied against herbivore insects (Agut et al., 2016; Erb et al., 2009), but less evidences are provided on their role against phytopathogens. However, a recent study showed that higher levels of $\alpha$-tomatine enhance tomato resistance against Phytophthora infestans and B. cinerea (Chen, Meng, He, Zhang, \& Luan, 2019). Furthermore, we showed that roots displayed a strong increase in PMT gene expression-coding for a key enzyme of the tropane alkaloid biosynthesis pathway-as both a local and systemic response to OGs. Interestingly, PMT gene expression in leaves was non-detectable, supporting the notion that roots are responsible for the synthesis of tropane alkaloids, which can be later transported systemically. The synthesis of tropane alkaloids in roots has been reported (Kohnen-Johannsen \& Kayser, 2019), and reciprocal grafting experiments show that the alkaloid patterns in leaves of solanaceae species are determined by the rootstock rather than the foliage (Bais, Sudha, Suresh, \& Ravishankar, 2001).

Here, we show that the responses observed upon OG treatments are biologically relevant for defence in tomato, since they confer systemic resistance against the necrotrophic pathogen $B$. cinerea. So far, only one report in Arabidopsis describes systemic protection against this fungus, with no further mechanistic study (Ferrari et al., 2007). Most of the knowledge relates instead to the protection induced by local elicitation with OGs (Aziz et al., 2004; Ferrari et al., 2007; Galletti et al., 2008; Galletti et al., 2011). Thus, our study clearly reveals striking differences between local and systemic defence/resistance responses in tomato. Besides the potentially fungicide compounds systemically accumulated in OG treated plants, such as the alkaloids, we also looked for other potential players that may contribute to the observed OG-systemic induced resistance against $B$. cinerea. Therefore, we explored the activity or gene expression levels of leucyl aminopeptidase (LAP) and the antimicrobial PR proteins $\beta$-1,3-glucanase (GluB) (van Kan et al., 1992). GluB expression was higher in the tissues showing increased resistance to $B$. cinerea (RT-SL and LT-SL), supporting its possible role in OGs-induced systemic resistance. It is worth noting that high doses of OGs $(500 \mu \mathrm{g} / \mathrm{ml})$ have been shown to induce glucanase activity in grapevine cells (Aziz et al., 2004) and that GluB gene expression is upregulated in the Solanum lycopersicoides Botrytis interaction (Smith, Mengesha, Tang, Mengiste, \& Bluhm, 2014). LAP is a JA-inducible enzyme that plays a key role in tomato plant responses towards biotic attack (Fowler et al., 2009). LAP activity increased upon leaf treatment only in systemic leaves and not in the treated ones. Thus, the induction of both LAP activity and GluB expression in systemic leaves, but not in the OG-treated leaves correlates with the systemic induced resistance observed.

Overall, our work reveals the complexity of the plant responses to damage perception, showing that, upon OG treatment, defence responses are triggered throughout the plant, but they differ depending on the site of DAMP application (summarized in Figure 6a, b). Our results are in agreement with the hypothesis of Tytgat et al. (2013) pointing that roots and aerial organs can activate different signalling cascades, thus likely contributing information about the site of induction. This would provide plants with a mechanism to finetune defence responses according to the damaged organ. The observation that systemic responses are stronger than local ones in both roots and shoots suggests that plants invest more resources in preparing distal tissues for efficient defence activation against a potential upcoming attack (Gómez, Ferrieri, Schueller, \& Orians, 2010; Kundu, Mishra, \& Vadassery, 2018; Steinbrenner, Gómez, Osorio, Fernie, \& Orians, 2011). 
In summary, we show that in tomato, responses to OGs trigger enhanced systemic resistance to pathogens. The response involves the regulation of JA, ABA and ET signalling pathways, and the activation of main metabolic pathways for the biosynthesis of antimicrobial metabolites such as alkaloids, flavonoids and lignans. Most of them are likely synthesized in the roots, even when OGs are applied in leaves, but can be later transported from the roots to the shoots. Thus, our wide analyses highlight the key role of roots in coordinating systemic defence responses to damage in plants. Identifying potential mobile signals orchestrating this root/shoot bidirectional dialogue is an exciting challenge for future research.

Our research highlights the need of addressing the spatiotemporal regulation of plant responses to DAMPs to understand how plants integrate danger signals and shape the appropriate defence responses. Moreover, this research paves the way for optimal biotechnological application of natural elicitors such as OGs for sustainable crop protection.

\section{ACKNOWLEDGMENTS}

We thank Dr. Daniela Pontiggia from Sapienza University of Rome for providing the purified oligogalacturonides. This work was supported by the Spanish Government through the CSIC Intramural project 201840E130 and the grant RTI2018-094350-B-C31 from the Ministerio de Ciencia, Innovación y Universidades. By the University Jaume I through the Plan de Promoción de la investigación UJIA2019-05 and two postdoctoral fellowships to J. Gamir, FJCl2015-23575 from Ministerio de Ciencia, Innovación y Universidades and CDEIGENT/2018/015 from Generalitat Valenciana.

\section{CONFLICT OF INTEREST}

None of the major findings of the research described here has been submitted to other journals or described elsewhere.

\section{ORCID}

\section{Jordi Gamir (D) https://orcid.org/0000-0003-0111-6454}

\section{REFERENCES}

Achuo, A. E., Audenaert, K., Meziane, H., \& Höfte, M. (2002). The SAdependent defense pathway is active against different pathogens in tomato and tobacco. Mededelingen (Rijksuniversiteit te Gent. Fakulteit van de Landbouwkundige en Toegepaste Biologische Wetenschappen), 67 (2), 149-157.

Agut, B., Gamir, J., Jaques, J. A., \& Flors, V. (2016). Systemic resistance in citrus to Tetranychus urticae induced by conspecifics is transmitted by grafting and mediated by mobile amino acids. Journal of Experimental Botany, 67(19), 5711-5723. https://doi.org/10.1093/jxb/erw335

Asselbergh, B., Curvers, K., Franca, S. C., Audenaert, K., Vuylsteke, M., Van Breusegem, F., \& Höfte, M. (2007). Resistance to Botrytis cinerea in sitiens, an abscisic acid-deficient tomato mutant, involves timely production of hydrogen peroxide and cell wall modifications in the epidermis. Plant Physiology, 144(4), 1863-1877. https://doi.org/10.1104/pp. 107.099226

Aziz, A., Heyraud, A., \& Lambert, B. (2004). Oligogalacturonide signal transduction, induction of defense-related responses and protection of grapevine against Botrytis cinerea. Planta, 218(5), 767-774. https:// doi.org/10.1007/s00425-003-1153-x
Bais, H. P., Sudha, G., Suresh, B., \& Ravishankar, G. A. (2001). Permeabilization and in situ adsorption studies during growth and coumarin production in hairy root cultures of Cichorium intybus L. Indian Journal of Experimental Biology, 39(6), 564-571.

Barbero, F., Guglielmotto, M., Capuzzo, A., \& Maffei, M. E. (2016). Extracellular self-DNA (esDNA), but not heterologous plant or insect DNA (etDNA), induces plasma membrane depolarization and calcium signaling in lima bean (Phaseolus lunatus) and maize (Zea mays). International Journal of Molecular Sciences, 17(10). https://doi.org/10.3390/ ijms17101659

Benedetti, M., Mattei, B., Pontiggia, D., Salvi, G., Savatin, D. V., \& Ferrari, S. (2017). Methods of isolation and characterization of oligogalacturonide elicitors. Methods in Molecular Biology, 1578, 25-38. https://doi.org/10.1007/978-1-4939-6859-6_3

Benedetti, M., Pontiggia, D., Raggi, S., Cheng, Z., Scaloni, F., Ferrari, S., ... De Lorenzo, G. (2015). Plant immunity triggered by engineered in vivo release of oligogalacturonides, damage-associated molecular patterns. Proceedings of the National Academy of Sciences of the United States of America, 112(17), 5533-5538. https://doi.org/10.1073/pnas. 1504154112

Biastoff, S., Brandt, W., \& Dräger, B. (2009). Putrescine N-methyltransferase-The start for alkaloids. Phytochemistry, 70(15-16), 1708-1718. https://doi.org/10.1016/j.phytochem.2009.06.012

Birkenmeier, G. F., \& Ryan, C. A. (1998). Wound signaling in tomato plants. Evidence that aba is not a primary signal for defense gene activation. Plant Physiology, 117(2), 687-693. https://doi.org/10.1104/pp.117. 2.687

Bishop, P. D., Makus, D. J., Pearce, G., \& Ryan, C. A. (1981). Proteinase inhibitor-inducing factor activity in tomato leaves resides in oligosaccharides enzymically released from cell walls. Proceedings of the National Academy of Sciences of the United States of America, 78(6), 3536-3540.

Bishop, P. D., Pearce, G., Bryant, J. E., \& Ryan, C. A. (1984). Isolation and characterization of the proteinase inhibitor-inducing factor from tomato leaves. Identity and activity of poly- and oligogalacturonide fragments. Journal of Biological Chemistry, 259(21), 13172-13177.

Cabrera, J. C., Boland, A., Messiaen, J., Cambier, P., \& Van Cutsem, P. (2008). Egg box conformation of oligogalacturonides: The timedependent stabilization of the elicitor-active conformation increases its biological activity. Glycobiology, 18(6), 473-482. https://doi.org/10. 1093/glycob/cwn027

Camejo, D., Martí, M. C., Olmos, E., Torres, W., Sevilla, F., \& Jimenez, A. (2012). Oligogalacturonides stimulate antioxidant system in alfalfa roots. Biologia Plantarum, 56, 537-544. https://doi.org/10.1007/ s10535-012-0107-1

Chao, W. S., Pautot, V., Holzer, F. M., \& Walling, L. L. (2000). Leucine aminopeptidases: The ubiquity of LAP-N and the specificity of LAP-A. Planta, 210(4), 563-573. https://doi.org/10.1007/s004250050045

Chen, L., Meng, J., He, X. L., Zhang, M., \& Luan, Y. S. (2019). Solanum lycopersicum microRNA1916 targets multiple target genes and negatively regulates the immune response in tomato. Plant, Cell \& Environment, 42(4), 1393-1407. https://doi.org/10.1111/pce.13468

Chong, J., Soufan, O., Li, C., Caraus, I., Li, S., Bourque, G., ... Xia, J. (2018). MetaboAnalyst 4.0: Towards more transparent and integrative metabolomics analysis. Nucleic Acids Research, 46(W1), W486-W494. https://doi.org/10.1093/nar/gky310

Curvers, K., Seifi, H., Mouille, G., de Rycke, R., Asselbergh, B., Van Hecke, A., ... Höfte, M. (2010). Abscisic acid deficiency causes changes in cuticle permeability and pectin composition that influence tomato resistance to Botrytis cinerea. Plant Physiology, 154(2), 847-860. https://doi.org/10.1104/pp.110.158972

Davidsson, P., Broberg, M., Kariola, T., Sipari, N., Pirhonen, M., \& Palva, E. T. (2017). Short oligogalacturonides induce pathogen resistance-associated gene expression in Arabidopsis thaliana. BMC Plant Biology, 17(1), 19. https://doi.org/10.1186/s12870-016-0959-1 
De Lorenzo, G., Ferrari, S., Cervone, F., \& Okun, E. (2018). Extracellular DAMPs in plants and mammals: Immunity, tissue damage and repair. Trends in Immunology, 39(11), 937-950. https://doi.org/10.1016/j.it. 2018.09.006

Denoux, C., Galletti, R., Mammarella, N., Gopalan, S., Werck, D., De Lorenzo, G., ... Dewdney, J. (2008). Activation of defense response pathways by OGs and Flg22 elicitors in Arabidopsis seedlings. Molecular Plant, 1(3), 423-445. https://doi.org/10.1093/mp/ssn019

Díaz, J., ten Have, A., \& van Kan, J. A. (2002). The role of ethylene and wound signaling in resistance of tomato to Botrytis cinerea. Plant Physiology, 129(3), 1341-1351. https://doi.org/10.1104/pp.001453

Doares, S. H., Syrovets, T., Weiler, E. W., \& Ryan, C. A. (1995). Oligogalacturonides and chitosan activate plant defensive genes through the octadecanoid pathway. Proceedings of the National Academy of Sciences of the United States of America, 92(10), 4095-4098.

Duran-Flores, D., \& Heil, M. (2017). Extracellular self-DNA as a damageassociated molecular pattern (DAMP) that triggers self-specific immunity induction in plants. Brain, Behavior, and Immunity, 72, 78-88. https://doi.org/10.1016/j.bbi.2017.10.010

El Oirdi, M., El Rahman, T. A., Rigano, L., El Hadrami, A., Rodriguez, M. C., Daayf, F., ... Bouarab, K. (2011). Botrytis cinerea manipulates the antagonistic effects between immune pathways to promote disease development in tomato. Plant Cell, 23(6), 2405-2421. https://doi.org/10. 1105/tpc.111.083394

Erb, M., Lenk, C., Degenhardt, J., \& Turlings, T. C. (2009). The underestimated role of roots in defense against leaf attackers. Trends in Plant Science, 14(12), 653-659. https://doi.org/10.1016/j.tplants.2009.08.006

Erb, M, Meldau, S, \& Howe, G. A. (2012). Role of phytohormones in insect-specific plant reactions. Trends in plant science, 17(5), 250. https://doi.org/10.1016/j.tplants.2012.01.003.

Ferrari, S., Galletti, R., Denoux, C., De Lorenzo, G., Ausubel, F. M., \& Dewdney, J. (2007). Resistance to Botrytis cinerea induced in Arabidopsis by elicitors is independent of salicylic acid, ethylene, or jasmonate signaling but requires PHYTOALEXIN DEFICIENT3. Plant Physiology, 144(1), 367-379. https://doi.org/10.1104/pp.107.095596

Ferrari, S., Plotnikova, J. M., De Lorenzo, G., \& Ausubel, F. M. (2003). Arabidopsis local resistance to Botrytis cinerea involves salicylic acid and camalexin and requires EDS4 and PAD2, but not SID2, EDS5 or PAD4. The Plant Journal, 35(2), 193-205. https://doi.org/10.1046/j.1365313x.2003.01794.x

Ferrari, S., Savatin, D. V., Sicilia, F., Gramegna, G., Cervone, F., \& Lorenzo, G. D. (2013). Oligogalacturonides: Plant damage-associated molecular patterns and regulators of growth and development. Frontiers in Plant Science, 4, 49. https://doi.org/10.3389/fpls.2013.00049

Fowler, J. H., Narváez-Vásquez, J., Aromdee, D. N., Pautot, V., Holzer, F. M., \& Walling, L. L. (2009). Leucine aminopeptidase regulates defense and wound signaling in tomato downstream of jasmonic acid. Plant Cell, 21(4), 1239-1251. https://doi.org/10.1105/tpc.108.065029

Galletti, R., Denoux, C., Gambetta, S., Dewdney, J., Ausubel, F. M., De Lorenzo, G., \& Ferrari, S. (2008). The AtrbohD-mediated oxidative burst elicited by oligogalacturonides in Arabidopsis is dispensable for the activation of defense responses effective against Botrytis cinerea. Plant Physiology, 148(3), 1695-1706. https://doi.org/10.1104/pp.108.127845

Galletti, R., Ferrari, S., \& De Lorenzo, G. (2011). Arabidopsis MPK3 and MPK6 play different roles in basal and oligogalacturonide- or flagellininduced resistance against Botrytis cinerea. Plant Physiology, 157(2), 804-814. https://doi.org/10.1104/pp.111.174003

Gamir, J., Pastor, V., Cerezo, M., \& Flors, V. (2012). Identification of indole3-carboxylic acid as mediator of priming against Plectosphaerella cucumerina. Plant Physiology and Biochemistry, 61, 169-179. https:// doi.org/10.1016/j.plaphy.2012.10.004

Gamir, J., Pastor, V., Kaever, A., Cerezo, M., \& Flors, V. (2014). Targeting novel chemical and constitutive primed metabolites against Plectosphaerella cucumerina. The Plant Journal, 78(2), 227-240. https:// doi.org/10.1111/tpj.12465
Gómez, S., Ferrieri, R. A., Schueller, M., \& Orians, C. M. (2010). Methyl jasmonate elicits rapid changes in carbon and nitrogen dynamics in tomato. The New Phytologist, 188(3), 835-844. https://doi.org/10. 1111/j.1469-8137.2010.03414.x

Gravino, M., Locci, F., Tundo, S., Cervone, F., Savatin, D. V., \& De Lorenzo, G. (2017). Immune responses induced by oligogalacturonides are differentially affected by AvrPto and loss of BAK1/BKK1 and PEPR1/PEPR2. Molecular Plant Pathology, 18(4), 582-595. https://doi. org/10.1111/mpp.12419

Gravino, M., Savatin, D. V., Macone, A., \& De Lorenzo, G. (2015). Ethylene production in Botrytis cinerea- and oligogalacturonide-induced immunity requires calcium-dependent protein kinases. The Plant Journal, 84 (6), 1073-1086. https://doi.org/10.1111/tpj.13057

Gust, A. A., Pruitt, R., \& Nürnberger, T. (2017). Sensing danger: Key to activating plant immunity. Trends in Plant Science, 22(9), 779-791. https:// doi.org/10.1016/j.tplants.2017.07.005

Häkkinen, S. T., Rischer, H., Laakso, I., Maaheimo, H., SeppänenLaakso, T., \& Oksman-Caldentey, K. M. (2004). Anatalline and other methyl jasmonate-inducible nicotine alkaloids from Nicotiana tabacum cv. By-2 cell cultures. Planta Medica, 70(10), 936-941. https://doi.org/ $10.1055 / \mathrm{s}-2004-832620$

Heil, M., \& Land, W. G. (2014). Danger signals-Damaged-self recognition across the tree of life. Frontiers in Plant Science, 5, 578. https://doi. org/10.3389/fpls.2014.00578

Hernandez-Mata, G., Mellado Rojas, M. E., Richards-Lewis, A., LopezBucio, J., Beltran-Peña, E., \& Soriano-Bello, E. L. (2010). Plant immunity induced by oligogalacturonides alters root growth in a process involving flavonoid accumulation in Arabidopsis thaliana. Journal of Plant Growth Regulation, 29, 441-454. https://doi.org/10.1007/ s00344-010-9156-x

Hewitt, E. J. (1966). Sand and water culture methods used in the study of plant nutrition. In J. P. Hudson (Ed.), Technical communication no. 22 (revised 2nd edition) of the Commonwealth Bureau of Horticulture and Plantation Crops, East Malling, Maidstone, Kent. Farnham Royal, England: Commonwealth Agricultural Bureaux. https://doi.org/10. 1017/S0014479700021852

Hilleary, R., \& Gilroy, S. (2018). Systemic signaling in response to wounding and pathogens. Current Opinion in Plant Biology, 43, 57-62. https:// doi.org/10.1016/j.pbi.2017.12.009

Jafari, Z., Haddad, R., Hosseini, R., \& Garoosi, G. (2013). Cloning, identification and expression analysis of ACC oxidase gene involved in ethylene production pathway. Molecular Biology Reports, 40(2), 1341-1350. https://doi.org/10.1007/s11033-012-2178-7

Jones, J. D., \& Dangl, J. L. (2006). The plant immune system. Nature, 444 (7117), 323-329. https://doi.org/10.1038/nature05286

Kaever, A., Landesfeind, M., Feussner, K., Morgenstern, B., Feussner, I., \& Meinicke, P. (2014). Meta-analysis of pathway enrichment: Combining independent and dependent omics data sets. PLoS One, 9(2), e89297. https://doi.org/10.1371/journal.pone.0089297

Kohnen-Johannsen, K. L., \& Kayser, O. (2019). Tropane alkaloids: Chemistry, pharmacology, biosynthesis and production. Molecules, 24(4). https://doi.org/10.3390/molecules24040796

Kundu, A., Mishra, S., \& Vadassery, J. (2018). Spodoptera litura-mediated chemical defense is differentially modulated in older and younger systemic leaves of Solanum lycopersicum. Planta, 248(4), 981-997. https://doi.org/10.1007/s00425-018-2953-3

Lê Cao, K. A., Boitard, S., \& Besse, P. (2011). Sparse PLS discriminant analysis: Biologically relevant feature selection and graphical displays for multiclass problems. BMC Bioinformatics, 12, 253. https://doi.org/10. 1186/1471-2105-12-253

Li, Q., Wang, C., \& Mou, Z. (2020). Perception of damaged self in plants. Plant Physiology, 182(4), 1545-1565. https://doi.org/10.1104/pp.19.01242

Li, N., Zhao, M., Liu, T., Dong, L., Cheng, Q., Wu, J., ... Zhang, S. (2017). A novel soybean dirigent gene. Frontiers in Plant Science, 8, 1185. https://doi.org/10.3389/fpls.2017.01185 
Livak, K. J., \& Schmittgen, T. D. (2001). Analysis of relative gene expression data using real-time quantitative $P C R$ and the 2(-Delta Delta $C(T)$ ) Method. 25(4), 402-408. https://doi.org/10.1006/meth.2001.1262.

Mithöfer, A., \& Boland, W. (2012). Plant defense against herbivores: Chemical aspects. Annual Review of Plant Biology, 63, 431-450. https://doi.org/10.1146/annurev-arplant-042110-103854

O'Donnell, P. J., Calvert, C., Atzorn, R., Wasternack, C., Leyser, H. M. O., \& Bowles, D. J. (1996). Ethylene as a signal mediating the wound response of tomato plants. Science, 274, 1914-1917. https://doi.org/ 10.1016/S1360-1385(97)88388-4

Orians, C. M., Pomerleau, J, \& Ricco, R(2000). Vascular Architecture Generates Fine Scale Variation in Systemic Induction of Proteinase Inhibitors in Tomato. Journal of Chemical Ecology, 26(2), 471-485. https:// doi.org/10.1023/A:1005469724427.

Orozco-Cardenas, M., \& Ryan, C. A. (1999). Hydrogen peroxide is generated systemically in plant leaves by wounding and systemin via the octadecanoid pathway. Proceedings of the National Academy of Sciences of the United States of America, 96(11), 6553-6557.

Pétriacq, P., Ton, J., Patrit, O., Tcherkez, G., \& Gakière, B. (2016). NAD acts as an integral regulator of multiple defense layers. Plant Physiology, 172(3), 1465-1479. https://doi.org/10.1104/pp.16.00780

Petrussa, E., Braidot, E., Zancani, M., Peresson, C., Bertolini, A., Patui, S., \& Vianello, A. (2013). Plant flavonoids-Biosynthesis, transport and involvement in stress responses. International Journal of Molecular Sciences, 14(7), 14950-14973. https://doi.org/10.3390/ijms140714950

Pieterse, C. M., Zamioudis, C., Berendsen, R. L., Weller, D. M., Van Wees, S. C., \& Bakker, P. A. (2014). Induced systemic resistance by beneficial microbes. Annual Review of Phytopathology, 52, 347-375. https://doi.org/10.1146/annurev-phyto-082712-102340

Reymond, P., Grünberger, S., Paul, K., Müller, M., \& Farmer, E. E. (1995). Oligogalacturonide defense signals in plants: Large fragments interact with the plasma membrane in vitro. Proceedings of the National Academy of Sciences of the United States of America, 92(10), 4145-4149. https://doi.org/10.1073/pnas.92.10.4145

Román, M., Fernández, I., Wyatt, T., Sahrawy, M., Heil, M., \& Pozo, M. J. (2011). Elicitation of foliar resistance mechanisms transiently impairs root association with arbuscular mycorrhizal fungi. Journal of Ecology, 99(1), 36-45. https://doi.org/10.1111/j.1365-2745.2010.01752.x

Sanmartín, N., Pastor, V., Pastor-Fernández, J., Flors, V., Pozo, M. J., \& Sánchez-Bel, P. (2020). Role and mechanisms of callose priming in mycorrhiza-induced resistance. Journal of Experimental Botany, 71(9), 2769-2781. https://doi.org/10.1093/jxb/eraa030

Sanmartín, N., Sánchez-Bel, P., Pastor, V., Pastor-Fernández, J., Mateu, D., Pozo, M. J., ... Flors, V. (2020). Root-to-shoot signalling in mycorrhizal tomato plants upon Botrytis cinerea infection. Plant Science, 298, 110595. https://doi.org/10.1016/j.plantsci.2020.110595

Savatin, D. V., Gramegna, G., Modesti, V., \& Cervone, F. (2014). Wounding in the plant tissue: The defense of a dangerous passage. Frontiers in Plant Science, 5, 470. https://doi.org/10.3389/fpls.2014.00470

Schilmiller, A. L., \& Howe, G. A. (2005). Systemic signaling in the wound response. Current Opinion in Plant Biology, 8(4), 369-377. https://doi. org/10.1016/j.pbi.2005.05.008

Scranton, M. A., Yee, A., Park, S. Y., \& Walling, L. L. (2012). Plant leucine aminopeptidases moonlight as molecular chaperones to alleviate stress-induced damage. Journal of Biological Chemistry, 287(22), 18408-18417. https://doi.org/10.1074/jbc.M111.309500

Simpson, S. D., Ashford, D. A., Harvey, D. J., \& Bowles, D. J. (1998). Short chain oligogalacturonides induce ethylene production and expression of the gene encoding aminocyclopropane1-carboxylic acid oxidase in tomato plants. Glycobiology, 8, 579-583. https://doi.org/10.1093/ glycob/8.6.579

Singh, R. R., Chinnasri, B., De Smet, L., Haeck, A., Demeestere, K., Van Cutsem, P., ... Kyndt, T. (2019). Systemic defense activation by COSOGA in rice against root-knot nematodes depends on stimulation of the phenylpropanoid pathway. Plant Physiology and Biochemistry, 142, 202-210. https://doi.org/10.1016/j.plaphy.2019.07.003
Smith, J. E., Mengesha, B., Tang, H., Mengiste, T., \& Bluhm, B. H. (2014). Resistance to Botrytis cinerea in Solanum lycopersicoides involves widespread transcriptional reprogramming. BMC Genomics, 15, 334. https://doi.org/10.1186/1471-2164-15-334

Smith, C. A., Want, E. J., O'Maille, G., Abagyan, R., \& Siuzdak, G. (2006). XCMS: Processing mass spectrometry data for metabolite profiling using nonlinear peak alignment, matching, and identification. Analytical Chemistry, 78(3), 779-787. https://doi.org/10.1021/ac051437y

Steinbrenner, A. D., Gómez, S., Osorio, S., Fernie, A. R., \& Orians, C. M. (2011). Herbivore-induced changes in tomato (Solanum lycopersicum) primary metabolism: A whole plant perspective. Journal of Chemical Ecology, 37(12), 1294-1303. https://doi.org/10.1007/s10886-011-0042-1

Sun, J. Q., Jiang, H. L., \& Li, C. Y. (2011). Systemin/jasmonate-mediated systemic defense signaling in tomato. Molecular Plant, 4(4), 607-615. https://doi.org/10.1093/mp/ssr008

Thain, J. F. (1995). Electrophysiology. Methods in Cell Biology, 49, 259-274.

Tian, D., Peiffer, M., De Moraes, C. M., \& Felton, G. W. (2014). Roles of ethylene and jasmonic acid in systemic induced defense in tomato (Solanum lycopersicum) against Helicoverpa zea. Planta, 239(3), 577-589. https://doi.org/10.1007/s00425-013-1997-7

Treutter, D. (2005). Significance of flavonoids in plant resistance and enhancement of their biosynthesis. Plant Biology (Stuttgart, Germany), 7(6), 581-591. https://doi.org/10.1055/s-2005-873009

Tytgat, T. O., Verhoeven, K. J., Jansen, J. J., Raaijmakers, C. E., BakxSchotman, T., Mclntyre, L. M., ... van Dam, N. M. (2013). Plants know where it hurts: Root and shoot jasmonic acid induction elicit differential responses in Brassica oleracea. PLoS One, 8(6), e65502. https://doi. org/10.1371/journal.pone.0065502

van Aubel, G., Cambier, P., Dieu, M., \& Van Cutsem, P. (2016). Plant immunity induced by COS-OGA elicitor is a cumulative process that involves salicylic acid. Plant Science, 247, 60-70. https://doi.org/10. 1016/j.plantsci.2016.03.005

van Kan, J. A., Joosten, M. H., Wagemakers, C. A., van den BergVelthuis, G. C., \& de Wit, P. J. (1992). Differential accumulation of mRNAs encoding extracellular and intracellular PR proteins in tomato induced by virulent and avirulent races of Cladosporium fulvum. Plant Molecular Biology, 20(3), 513-527. https://doi.org/10.1007/ BF00040610

Vega-Muñoz, I., Feregrino-Pérez, A. A., Torres-Pacheco, I., \& GuevaraGonzález, R. G. (2018). Exogenous fragmented DNA acts as a damageassociated molecular pattern (DAMP) inducing changes in CpG DNA methylation and defence-related responses in Lactuca sativa. Functional Plant Biology, 45(10), 1065-1072. https://doi.org/10.1071/ FP18011

Wang, G., Hu, C., Zhou, J., Liu, Y., Cai, J., Pan, C., ... Yu, J. (2019). Systemic root-shoot signaling drives Jasmonate-based root defense against nematodes. Current Biology, 29(20), 3430-3438.e4. https://doi.org/ 10.1016/j.cub.2019.08.049

Zipfel, C., \& Oldroyd, G. E. (2017). Plant signalling in symbiosis and immunity. Nature, 543(7645), 328-336. https://doi.org/10.1038/nature22009

\section{SUPPORTING INFORMATION}

Additional supporting information may be found online in the Supporting Information section at the end of this article.

How to cite this article: Gamir J, Minchev Z, Berrio E, García JM, De Lorenzo G, Pozo MJ. Roots drive oligogalacturonide-induced systemic immunity in tomato. Plant Cell Environ. 2021;44:275-289. https://doi.org/10. 1111/pce.13917 